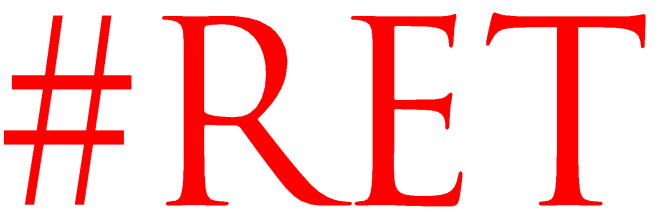

Revista Española de la Transparencia

Núm. 13. Segundo semestre. Julio-diciembre de 2021, pp. 271-318

ISSN 2444-2607. www.revistatransparencia.com

DOI: https://doi.org/10.51915/ret.184

\title{
Evolución de la transparencia en jurisdicciones municipales de Argentina entre 2019 y 2020
}

\author{
Vanessa N. Toselli ${ }^{1}$ \\ Universidad Nacional de Córdoba (UNC) \\ Instituto de Estudios sobre la Realidad Argentina y Latinoamericana (IERAL) \\ Argentina \\ ORCID: $\underline{0000-0002-6019-2767}$ \\ Paula González² \\ Instituto de Estudios sobre la Realidad Argentina y Latinoamericana (IERAL) \\ Argentina \\ ORCID: $\underline{0000-0002-0259-8398}$
}

RECIBIDO: 5 de mayo de 2021 ACEPTADO: 30 de agosto de 2021

RESUMEN: El artículo presenta los resultados de una investigación sobre el nivel de transparencia de los 70 municipios más poblados de la República Argentina realizada por medio de la construcción de un índice compuesto por siete ejes: autoridades, órganos de gobierno, rendición de cuentas, presupuesto, contrataciones y licitaciones públicas, comunicación institucional, información general y participación ciudadana. El relevamiento se realizó dos años consecutivos, 2019 y 2020, permitiendo conocer su evolución e identificar fortalezas y/o debilidades tanto a nivel general como particular de cada municipio. Se ofrece así un diagnóstico a partir del cual conocer cuáles políticas son necesarias llevar a cabo para avanzar y/o mejorar en transparencia, principio fundamental para los gobiernos democráticos modernos, incluido a nivel municipal.

\footnotetext{
${ }^{1}$ Dra. en Ciencias Políticas, y Lic. en Economía por la Universidad Nacional de Córdoba (UNC), Argentina. Docente de grado y postgrado en UNC. Miembro de equipos de extensión e investigación tanto en la Universidad Nacional de Córdoba, como en la Universidad Católica de Córdoba. Investigadora Senior en IERAL de Fundación Mediterránea. Autora y coautora de múltiples publicaciones en materia económica, fiscal, y de gobernabilidad.

2 Licenciada en Ciencia Política por la Universidad Católica de Córdoba (UCC), Argentina. Investigadora Junior en IERAL de Fundación Mediterránea.
} 
PALABRAS CLAVE: transparencia, municipios, República Argentina, evolución.

CONTENIDOS: 1. Introducción. - 2. Marco teórico. - 3. Transparencia en Argentina. 4. Metodología. - 5. Resultados. -5.1. Diagnóstico de principales municipios. Año 2019 - 5.2. Diagnóstico de principales municipios. Año 2020. - 5.3. Diagnóstico comparado 2019-2020 - 5.4. Relación con estudios en Ecuador y España. - 6. Comentarios finales. - Bibliografía. - Anexo I. Detalle de indicadores considerados.

\section{Evolution of transparency in municipal jurisdictions of Argentina between 2019 and 2020}

ABSTRACT: This article presents the results of an investigation on the level of transparency of the 70 most populated municipalities of the Argentine Republic carried out by means of the construction of an index composed of seven axes: authorities, government bodies, accountability, budget, contracting and public tenders, institutional communication, general information and citizen participation. The survey was carried out for two consecutive years, 2019 and 2020, allowing us to know its evolution and identify strengths and/or weaknesses both at a general and particular level of each municipality. Thus, a diagnosis is offered in order to know which policies are necessary to implement to advance and/or improve transparency, a fundamental principle for modern democratic governments, including at the municipal level.

KEYWORDS: transparency, municipalities, Argentine Republic, evolution. 


\section{Introducción}

La creciente participación y exigencia de la ciudadanía en asuntos de política pública ha llevado a generar una mayor presión en los gobiernos al momento de rendir cuentas en materia de gasto público, programas implementados y gestión pública en general. Esta necesidad, impulsada y facilitada en gran medida por las tecnologías de la información y la comunicación (TIC's), las llamadas tecnologías sociales, ha llevado a emerger un nuevo paradigma en gestión gubernamental. Este nuevo paradigma denominado de «gobierno abierto», comprende una modalidad de gestión pública con mayor grado de participación, transparencia y colaboración entre Estado, sociedad civil y sector privado, contribuyendo al fortalecimiento democrático (Oszlak, 2014; Ramírez-Alujas, 2010).

A través de un índice compuesto por 52 indicadores, la presente investigación analizó la transparencia para 70 municipios principales de la República Argentina en dos periodos consecutivos, 2019 y 2020. Obteniendo así información sobre el estado de situación en la materia como también su evolución, permitiendo identificar las deficiencias a las que se enfrentan los hacedores de política y que deberian resolver siguiendo lineamientos concretos de acción. De esta manera los resultados del relevamiento, que da sustento al presente estudio, cobran especial relevancia para analizar y posteriormente desarrollar y evaluar los planes llevados a cabo para avanzar de manera eficaz y certera en esta área fundamental. Al tratarse de un índice que evalúa a los municipios en relación al conjunto permite identificar grados de desarrollo y reconocer casos modelos a las cuales imitar o aspirar.

El informe se organiza de la siguiente manera, en la siguiente sección se presentan algunos aspectos claves -conceptuales y normativos- vinculados con la transparencia y el gobierno abierto. En la tercera sección se explica la metodología utilizada para realizar las mediciones en los gobiernos locales de Argentina. Posteriormente, se presentan los resultados del relevamiento para el año 2019 y 2020, y un análisis comparativo entre ediciones. Por último, se introducen algunas conclusiones y reflexiones finales.

\section{Marco Teórico}

Existe mundialmente en las administraciones públicas una tendencia hacia el gobierno abierto, visualizándose diversos niveles de madurez y grados de implementación en las diferentes localizaciones según lo ha manifestado el último informe publicado por OCDE a fines de 20163. Tanto por sus potenciales democráticos como por sus ventajas administrativas, el gobierno abierto empieza

${ }^{3}$ Gobierno Abierto. Contexto mundial y el camino a seguir. OCDE. 2016 
poco a poco a consolidarse como un nuevo paradigma de gestión pública (Nasser y Ramírez-Alujas, 2014; Ramírez-Alujas y Dassen, 2014).

Siguiendo a Ramírez-Alujas (2012:15), los elementos constitutivos del gobierno abierto están dados por la transparencia y acceso a la información, la participación ciudadana en el diseño e implementación de políticas públicas, y la colaboración entre los diversos actores (administraciones públicas, sociedad civil y sector privado). Dicha concepción implica que el gobierno abierto no trata sólo de apertura en términos informativos, sino también de apertura en términos interactivos (Meijer, Curtin, y Hillebrandt, 2012:11).

La transparencia en la gestión pública puede definirse como la posibilidad de que la ciudadanía pueda acceder a cualquier tipo de información, en cualquier soporte, generada por las entidades en el cumplimiento de sus funciones (Giménez-Chornet, 2012:505). Esto guarda relación con el derecho ciudadano de conocer los propósitos de las administraciones y las estrategias que van a seguir para conseguirlos (RiveroMenéndez et al., 2007:2). La información debe ser publicada de tal manera que sea realmente un aporte a la ciudadanía y al sistema democrático, de modo de favorecer la participación con fundamento (Bertot et al., 2010:264).

La creciente expansión de las tecnologías de la información representa una oportunidad para mejorar la gestión pública, recuperar la confianza de los ciudadanos y estimular la opinión púbica crítica (Criado y Ramilo, 2003; Moon, Lee y Roh, 2014). Para esto es necesario que el ciudadano pueda conocer cómo actúan los poderes públicos, qué responsabilidades tienen en el ejercicio de dicho poder, y puedan preguntar libremente sobre aquello que le parezca oportuno para formarse su propia opinión, a partir de la consideración de la información pública de calidad como derecho ciudadano (De Miguel Molina, 2010). La transparencia informativa consiste en la puesta a disposición de la ciudadanía del conjunto de datos, documentos, expedientes y otros archivos que explican y muestran la acción del Gobierno, del sistema y de sus actores, instituciones y tradiciones (Manfredi Sánchez, 2010:113). La administración electrónica utiliza las TICs para reabrir tareas administrativas y de comunicación e interacción de las administraciones públicas con ciudadanos y con otras entidades (Durán Ruiz, 2009)

Consecuentemente, el gobierno abierto adquirió una nueva visión al referirse no sólo el derecho de las personas a tener acceso a los documentos del gobierno y tener acceso a la información (Lathrop y Ruma, 2010:109), sino a lograr la transparencia de los datos, la participación y colaboración, que permitan a los ciudadanos conocer, comunicar y compartir las mejores decisiones, esto es, lograr un gobierno colaborativo.

Así la transparencia y el acceso a la información involucran una comunicación entre las administraciones públicas y la ciudadanía siendo las primeras capaces de ofrecer información concreta de interés público en cuanto a quiénes son los representantes 
políticos, cómo se gestionan los recursos colectivos, cómo informan de la gestión de los recursos colectivos y qué herramientas ofrecen para la participación ciudadana en el control democrático (Manfredi Sánchez, 2016:479). En la administración pública, la comunicación es fundamental como elemento de legitimidad y de gobernabilidad, y es un elemento al que ningún funcionario puede renunciar (Canel, 2018). Para que esta comunicación sea efectiva debe cumplir tres principios fundamentales: debe ser claro para la comprensión del mensaje; íntegro, ya que al mensaje que se comunica se le debe dar importancia por su contenido; y su uso debe ser estratégico en relación con las funciones de la organización (Camacho Ávila, 2006). Molina Rodríguez Navas (2018:146) agrega que la información publicada para lograr la transparencia debe ser veraz, comprensible, fácilmente accesible y debe estar disponible para que la ciudadanía, medios de comunicación u otras instituciones puedan acceder a ella en el momento que estimen conveniente.

Lograr que la transparencia sea un elemento caracteristico de los gobiernos de manera que se reduzcan los niveles de corrupción y se produzca una mejora en la provisión de los servicios públicos, requiere un cambio cultural e institucional rotundo en la gestión pública (Molina y Vieyra, 2012:3) Implica el involucramiento de todos los actores (Estado, sociedad civil y sector privado) en la oferta y demanda de transparencia. Mediante políticas de transparencia, los gobiernos pueden proveer de información útil a los ciudadanos de manera clara y actualizada, mientras que éstos, aprovechando el uso de las TICs, ven reducidos los costos de acceso a la información pública, y pueden utilizar más eficientemente las ventajas que la apertura y la rendición de cuentas suponen. De esta manera los esfuerzos se encaminan a la modernización de la administración pública, facilitando al ciudadano la participación activa en el diseño, implementación y control de políticas pública locales.

Garantizar el acceso a la información a todos los ciudadanos, dada la heterogeneidad de las poblaciones, requiere una disminución en la brecha digital entre sus miembros, lo cual implica una mejora en infraestructura en general, y de telecomunicaciones y datos en particular' La Organización para la Cooperación y el Desarrollo Económicos (OCDE, 2001:5) define esta brecha como el «desfase o división entre individuos, hogares, áreas económicas y geográficas con diferentes niveles socioeconómicos con relación tanto a sus oportunidades de acceso a las tecnologías de la información y la comunicación, como al uso de internet para una amplia variedad de actividades»

La experiencia de los gobiernos de América Latina y el Caribe denota esfuerzos encaminados a la transparencia y el control de las gestiones subnacionales, impulsados tanto por una demanda de las organizaciones de la sociedad civil como por ímpetu de los gobiernos. Respecto a los gobiernos, se destacan esfuerzos de

${ }^{4}$ Armenta et al. (2012), Bauerlein, (2011) 
Argentina, Bolivia, Brasil y Colombia, entre otros. En el caso de Brasil, la Oficina del Controlador General (CGU, por sus siglas en portugués), órgano encargado de garantizar el cumplimiento de la ley de acceso a la información pública, ha destacado como uno de los mayores desafios en la implementación de la ley, fortalecer las capacidades de los niveles subnacionales de gobierno. Respecto a la sociedad civil, se destaca la Iniciativa de Integridad Subnacional de la organización Global Integrity, la cual involucra a países de la región como Argentina, Ecuador, Guatemala, México y Perú, y la Iniciativa para la Transparencia presupuestaria a nivel subnacional por parte de la International Budget Partnership, a partir de la cual se realizaron estudios piloto en Argentina, Bolivia, Brasil, Ecuador y Perú.

Con la fuerte participación de países de América Latina y el Caribe, la Alianza para el Gobierno Abierto (Open Government Partnership) del Banco Interamericano de Desarrollo, cuenta con 15 países latinos miembros, de los cuales 14 ya están llevando a cabo la evaluación o implementación de sus planes de acción encaminados a un gobierno abierto.

Dadas las dificultades que presentan los gobiernos subnacionales de América Latina y el deseable rumbo hacia el cual dirigir la política pública y su entorno en vistas de avanzar hacia un gobierno abierto, con los aparejados beneficios que implica, se presentan desafios no menores para los gobiernos latinos subnacionales (Hernández Bonivento, 2014). Resulta conveniente realizar inicialmente un diagnóstico de situación que permita evaluar el estado actual de cada territorio para luego diseñar un plan de acción adaptado a las características y problemáticas locales, encaminado al logro de una mayor transparencia en el accionar de la gestión pública.

En vistas de esto, el presente estudio ofrece un primer paso en este sentido ofreciendo un método para conocer y evaluar la situación de los municipios que son los entes que mantienen la relación más cercana entre la administración pública y la ciudadanía. Como referencia se toma la metodología Infoparticipa desarrollada en España surgida para analizar la información que ofrecen las administraciones públicas locales en sus webs para que la ciudadanía pueda evaluar la acción del gobierno y exigir la rendición de cuentas (Moreno Sardá et al., 2012). Este estudio que se viene desarrollando de manera continua desde 2012 y publica sus resultados ha promovido la emulación y la competitividad, y favorecido la voluntad de mejorar de los ayuntamientos. Los ayuntamientos pueden mejorar viendo qué hace información falta introducir, pero también contrastando la propia web con otras que han obtenido puntuaciones superiores o publican informaciones especificas. Además de España, la metodología se aplicó a municipios de Ecuador (Molina Rodríguez Navas y Medranda, 2018).

En el caso de España, los primeros resultados en 2012 mostraban que menos de 50 webs de los 947 ayuntamientos analizados de Catalunya puntuaba positivamente el 
50\% de los indicadores. El tamaño de los ayuntamientos mostró ser el factor más relevante para determinar el nivel de transparencia por la disponibilidad de mayores recursos. No obstante, también se observó una tendencia hacia una mayor concientización de los municipios más pequeños.

En 2003 España aprobó una ley de transparencia a cuyas exigencias se tuvieron que adaptar los ayuntamientos al finalizar 2015. Según los análisis de Infoparticipa, los resultados no fueron satisfactorios como se esperaba con la aplicación de la ley (Moreno-Sardá et al., 2017:376). Se redujeron las webs con al menos el 50\% de indicadores positivos y también las que tenían entre el 25 y menos del 50\% de indicadores positivos, aumentando las que no llegaban ni al $25 \%$. Los municipios más grandes en términos de población son los que obtienen mejores resultados no obstante se observó una serie de municipios de medianas dimensiones con mejores resultados. Por otra parte, los indicadores con peores resultados fueron los referidos a la publicidad de la agenda del alcalde o alcaldesa, las retribuciones de directores y cargos de confianza, la relación de proveedores, los convenios firmados o la carta de servicios; todas informaciones que forman parte del catálogo de datos esenciales que toda administración pública debe tener en su web de acuerdo a la Ley y para resultad confiable (Moreno Sardá et al., 2017:376).

En el caso de Ecuador, los resultados mostraron la escasa información provista por las páginas web de los municipios en torno a los representantes políticos y nula existencia de información sobre los bienes de los cargos electos y sus actividades, información esencial para aportar confianza a la ciudadanía. También destaca la absoluta falta de transparencia sobre la agenda de la máxima autoridad del municipio. Acerca de la gestión de los recursos colectivos, se observaron algunas buenas prácticas con porcentajes elevados, sin embargo, otras informaciones esenciales como las relativas a la planificación urbanística o a la composición del resto de órganos de gobierno y su funcionamiento obtienen puntuaciones muy bajas, considerando su importancia.

En lo que refiere a temas económicos, el presupuesto anual lo publica menos de la mitad de los municipios ecuatorianos, y aunque más de la mitad publica las remuneraciones del personal contratado, ninguno informa de las remuneraciones de los cargos de confianza. También destaca la escasa información que se proporciona sobre las licitaciones, subvenciones y convenios. Incluso, algunas informaciones sensibles como las adjudicaciones de subvenciones o convenios, sólo son informados en un 3 y $11 \%$ de los casos. El tema de los costos de campaña publicitarias de la institución en los medios de comunicación es insuficiente. En cuanto a las noticias, un alto porcentaje publica informaciones sobre las actuaciones del gobierno, pero los datos son muy negativos cuando se trata de informar sobre la actividad del resto de grupos políticos. También se ha constatado que a través de estos sitios institucionales resulta difícil conocer aspectos clave sobre la realidad del municipio o disponer de la agenda de actividades, lo que pone de manifiesto la falta 
de una idea clara sobre la función de la web del municipio como herramienta de dinamización, participación y producción del conocimiento. Por último, con respecto a herramientas de participación las puntuaciones son muy bajas demostrando cierta falta de voluntad política para contar con la ciudadanía en el debate y la planificación de las políticas públicas.

\section{Transparencia en Argentina}

En Argentina, en 2016 se publicó el Decreto 434/2016 titulado como Plan de Modernización del Estado por el cual se empezaron a realizar medidas de acción concretas en materia de acceso a la información a nivel nacional. Con esta normativa se pretendió impulsar nuevas formas de gestión y desarrollo que acerquen al ciudadano a la gestión del Gobierno Nacional, así como la implementación de proyectos que permitan asistir a los gobiernos provinciales y municipales que lo requieran.

Ese mismo año se sancionó la Ley Nacional N²7.275 de Derecho de Acceso a la Información Pública. Esta ley además de establecer el acceso a la información pública como un derecho, promueve procedimientos sencillos y rápidos de acceso a la información, propicia la transparencia mediante la difusión de la información, impulsa la rendición de cuentas, y promueve la participación ciudadana y el control en la gestión de los recursos que utilizan las instituciones del Estado (Fenoglio, 2020). De acuerdo a esta normativa, el derecho de acceso a la información pública comprende la posibilidad de buscar, acceder, solicitar, recibir, copiar, analizar, reprocesar, reutilizar y redistribuir libremente la información bajo custodia de los sujetos obligados por esta ley.

En términos de políticas públicas, en 2020 se presentó por parte de la Secretaría de Innovación Pública de la Nación, el Cuarto Plan de Acción de Gobierno Abierto 20192020, Este plan estuvo conformado por 18 compromisos entre los cuales se incluyó el diseño de un Programa Federal de Gobierno Abierto cuyos objetivos eran: desarrollar un enfoque articulado y coordinado entre el plano nacional, provincial y municipal para fortalecer políticas de gobierno abierto; fomentar la co-creación de políticas en provincias y municipios; ampliar y diversificar la comunidad de actores del gobierno y de la sociedad civil que se involucran en la agenda de gobierno abierto; y promover la implementación de políticas de gobierno abierto en ámbitos subnacionales acorde a las demandas sectoriales y en línea con los Objetivos de Desarrollo Sostenible (ODS).

Más allá de estas iniciativas, se observan limitaciones al evaluar la implementación de los mecanismos que hacen al gobierno abierto. Pando (2017), en este sentido, alega la necesidad de construir y aplicar indicadores válidos y confiables que midan los efectos de estas iniciativas en la sociedad para lograr efectivamente sus objetivos y los requerimientos de los destinatarios (ciudadanos, organizaciones civiles, empresas). Según este autor se da poca importancia a la implementación en 
comparación con el énfasis que se pone a la formulación de este tipo de políticas debido a una mirada mecanicista por la cual la implementación consiste en la mera "aplicación" de un diseño. En consecuencia, la implementación aparece como un efecto residual del diseño. Asociado a esto está la disponibilidad de recursos humanos, financieros y materiales. Los cambios institucionales y culturales implícitos en el Gobierno Abierto exigen nuevos roles y nuevos mecanismos de interacción, tanto dentro del Estado como de la sociedad civil.

Por otra parte, se observa que los planes de acción en materia de gobierno abierto carecen de metas claramente definidas y de responsabilidades delimitadas (Ramírez Alujas y Dassen, 2014:23) quitando toda posibilidad de determinar el éxito o fracaso de los programas y proyectos teniendo en cuenta la perspectiva del ciudadano.

\section{Metodología}

La metodología aplicada en el presente trabajo está basada en la herramienta Mapa Infoparticipa del Laboratorio de Periodismo y Comunicación para la Ciudadanía Plural de la Universidad Autónoma de Barcelona5 (Robles-López, C., 2020). A partir de la misma, se realizó una selección y adaptación de los indicadores aplicados al caso ecuatoriano (Rodríguez-Navas y Medranda, 2018) en diferentes aspectos en función de su aplicación a 70 municipios de diferentes provincias de la República Argentina.

La metodología se enfoca en evaluar la disponibilidad y accesibilidad de información provista por los sitios web oficiales de los municipios, a partir de los cuales se relevan diferentes aspectos relativos a la transparencia, puntuando los mismos de acuerdo a la cantidad y calidad de información disponible.

La unidad básica de recogida y análisis de información es la ficha de cada municipio compuesta de 52 indicadores a relevar que responden a diferentes ejes dependiendo del carácter de lo comunicado: 1) autoridades, 2) órganos de gobierno, 3) rendición de cuentas, 4) presupuesto, 5) contrataciones y licitaciones públicas, 6) comunicación institucional, 7) información general y 8) participación ciudadana.

No se incorporaron datos de contexto como el papel del municipio como capital de alguna entidad administrativa supralocal, el sexo o el partido político del intendente ni se buscó establecer correlaciones al momento de analizar los datos.

En la Tabla 1 se muestra el agrupamiento, la cantidad y distribución de indicadores relevados para cada uno de los ejes y la relación que éstos guardan con las categorias originales en las cuales ordena los indicadores la metodología de

\footnotetext{
5 Mapa Infoparticipa: https://www.mapainfoparticipa.com/index/home/4
} 
Infoparticipa y que para este estudio se decidió desdoblar en ocho ejes para una mayor comprensión en el contexto local.

Tabla 6: Cantidad de indicadores relevados por categoria de análisis y vínculo con la metodología original

\begin{tabular}{|c|c|c|c|c|c|}
\hline $\begin{array}{c}\text { Categoria } \\
\text { Infoparticipa }\end{array}$ & \# & Categoría - Eje & $\begin{array}{l}\text { Principales } \\
\text { sub-ejes }\end{array}$ & $\begin{array}{c}\text { Cantidad } \\
\text { de } \\
\text { indicadores } \\
\text { relevados }\end{array}$ & $\begin{array}{c}\text { \# Indicador en } \\
\text { Metodologia } \\
\text { de referencia }\end{array}$ \\
\hline \multirow{4}{*}{$\begin{array}{l}\text { Representan } \\
\text { tes politicos }\end{array}$} & \multirow{4}{*}{1} & \multirow{4}{*}{ Autoridades } & $\begin{array}{l}\text { Información de } \\
\text { contacto }\end{array}$ & \multirow{4}{*}{11} & \multirow{4}{*}{$1-11$} \\
\hline & & & DDJJ & & \\
\hline & & & Agendas oficiales & & \\
\hline & & & $\mathrm{CV}$ & & \\
\hline \multirow{5}{*}{$\begin{array}{l}\text { Recursos } \\
\text { colectivos }\end{array}$} & \multirow{3}{*}{2} & \multirow{3}{*}{$\begin{array}{c}\text { Órganos } \\
\text { de Gobierno }\end{array}$} & Organigramas & \multirow{3}{*}{5} & \multirow{3}{*}{$12-16$} \\
\hline & & & $\begin{array}{l}\text { Actas y órdenes del } \\
\text { dia }\end{array}$ & & \\
\hline & & & Agendas & & \\
\hline & \multirow[t]{2}{*}{3} & \multirow{2}{*}{$\begin{array}{l}\text { Rendición de } \\
\text { cuentas }\end{array}$} & $\begin{array}{l}\text { Objetivos y planes } \\
\text { documentados }\end{array}$ & \multirow[t]{2}{*}{4} & \multirow[t]{2}{*}{$17-20$} \\
\hline & & & Normativa vigente & & \\
\hline \multirow{6}{*}{$\begin{array}{l}\text { Recursos } \\
\text { económicos }\end{array}$} & \multirow{2}{*}{4} & \multirow{2}{*}{ Presupuesto } & $\begin{array}{l}\text { Presupuesto } \\
\text { vigente }\end{array}$ & \multirow{2}{*}{6} & \multirow{2}{*}{$21-26^{*}$} \\
\hline & & & $\begin{array}{ll}\text { Ejecuciones } & \text { y } \\
\text { sostenibilidad } & \\
\end{array}$ & & \\
\hline & \multirow{4}{*}{5} & \multirow{4}{*}{$\begin{array}{c}\text { Contrataciones } \\
\text { y licitaciones } \\
\text { públicas }\end{array}$} & Concursos & \multirow{4}{*}{10} & \multirow{4}{*}{$28-37$} \\
\hline & & & $\begin{array}{l}\text { Licitaciones y } \\
\text { compras públicas }\end{array}$ & & \\
\hline & & & Convenios & & \\
\hline & & & Proveedores & & \\
\hline \multirow{3}{*}{ Información } & \multirow{3}{*}{6} & \multirow{3}{*}{$\begin{array}{l}\text { Comunicación } \\
\text { institucional }\end{array}$} & $\begin{array}{lll}\begin{array}{l}\text { Noticias } \\
\text { gestión }\end{array} & & \\
\end{array}$ & \multirow{3}{*}{5} & \multirow{3}{*}{$38-42$} \\
\hline & & & $\begin{array}{lll}\text { Noticias } & \text { de } & \text { la } \\
\text { oposición } & & \\
\end{array}$ & & \\
\hline & & & $\begin{array}{ll}\text { Gastos } & \text { en } \\
\text { publicidad } & \\
\end{array}$ & & \\
\hline \multirow{5}{*}{$\begin{array}{l}\text { Participación } \\
\text { Ciudadana }\end{array}$} & \multirow[t]{2}{*}{7} & \multirow{2}{*}{$\begin{array}{l}\text { Información } \\
\text { general }\end{array}$} & $\begin{array}{ll}\text { Datos } & \text { del } \\
\text { municipio } & \\
\end{array}$ & \multirow[t]{2}{*}{4} & \multirow[t]{2}{*}{$43-46$} \\
\hline & & & Agenda ciudadana & & \\
\hline & \multirow{3}{*}{8} & & $\begin{array}{ll}\text { Instrumentos } & \text { de } \\
\text { participación } & \\
\end{array}$ & & \\
\hline & & $\begin{array}{l}\text { Participación } \\
\text { ciudadana }\end{array}$ & $\begin{array}{l}\text { Organizaciones } \\
\text { civiles }\end{array}$ & 7 & $47-53$ \\
\hline & & & $\begin{array}{ll}\text { Mecanismos de } \\
\text { reclamos }\end{array}$ & & \\
\hline & & Total & & 52 & 53 \\
\hline
\end{tabular}

Fuente: Elaboración propia en base de indicadores elaborados por el Laboratorio de Periodismo y Comunicación para la Ciudadanía Plural de la Universidad Autónoma de Barcelona 
Dado que la metodología tomada como referencia pondera en igual manera a cada uno de los 53 indicadores (52 en este caso, por haber eliminado el indicador 27), el peso relativo de cada eje responde a la cantidad de indicadores que han sido considerados en su interior, tal como se presenta en el siguiente esquema.

\section{Esquema 1: Cantidad de indicadores relevados por categoría de análisis y vínculo con la metodología original}
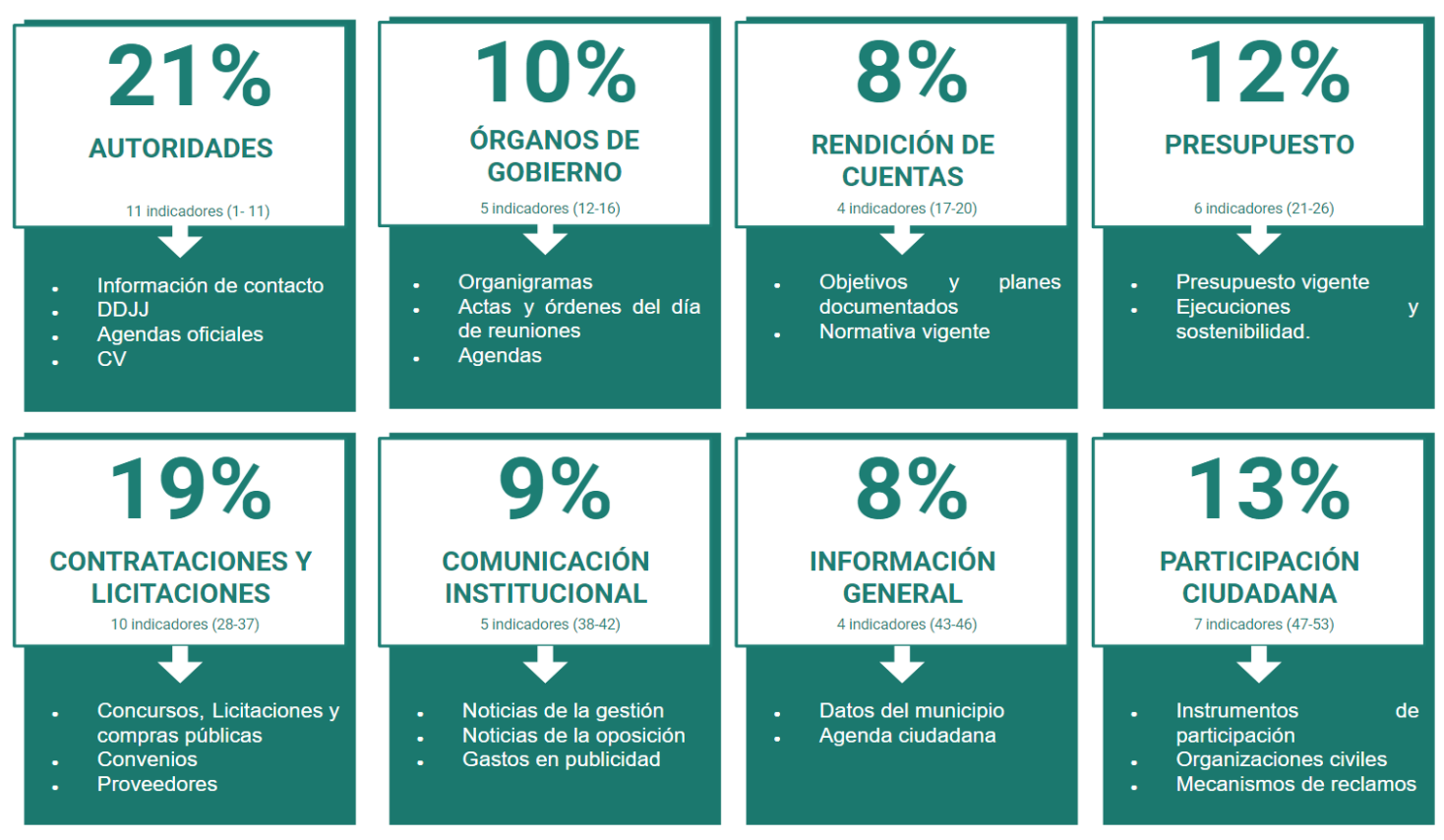

Fuente: Elaboración propia

Para el eje de autoridades, se tiene en cuenta la disponibilidad de datos acerca de los actuales funcionarios - de gobierno y de la oposición - tales como nombre completo, foto, currículo, agenda institucional asociada, datos de contacto, remuneraciones y declaraciones juradas. Respecto de los órganos de gobierno, se releva la disponibilidad de información acerca de su composición, sus funciones y calendario de trabajo. En cuanto a la rendición de cuentas, se observa la disponibilidad de los respectivos informes como actas de sesiones del Concejo Deliberante, y reportes de planes y programas en ejecución. Sobre el presupuesto, los indicadores asociados evalúan la disponibilidad de normas respectivas a la gestión de recursos como el presupuesto vigente y sus modificaciones, ejecución mensual y liquidación correspondiente a ejercicios anteriores o bien la cuenta general. Para contrataciones y licitaciones públicas se releva la información disponible en todas las etapas del proceso, desde la publicación de los llamados a licitación vigentes, hasta las contrataciones efectivamente realizadas, modificaciones reglamentarias y valoración del proceso. La comunicación institucional es relevada con indicadores que evalúan la disponibilidad de información relativa a costes y caracteristicas de campañas publicitarias 
institucionales en los medios. Asimismo, en relación a la participación ciudadana se interroga sobre la disponibilidad de instrumentos para valorar los servicios públicos, mecanismos de consultas, actas de entes de participación y nomas que la regulan. En información general se consideran la existencia de información acerca de aspectos geográficos, históricos, climáticos, entre otros, de la jurisdicción.

Al momento de valuar, se adaptó el criterio metodológico original (que presenta valoración positiva o negativa - valuado en 1 o o respectivamente-) a la realidad local argentina, que se ubica en una etapa preliminar en el proceso de modernización y gobierno abierto. De esta manera, se amplió el abanico de posibilidades de respuesta, pudiendo cada uno de los 52 indicadores considerados asumir tres valores posibles: 1 en caso de contar con toda la información considerada en la definición del indicador y cumplir con las condiciones básicas de accesibilidad propuestas en la metodología original; 0,5 para las situaciones en donde se disponga de información parcial (pero que cumpla con ciertos requisitos mínimos); y o para los casos donde no se disponga en absoluto, o mínimamente, de la información correspondiente al indicador en la web oficial del municipio.

Tabla 2: Asignación de valores por indicador

\begin{tabular}{|c|l|}
\hline Valor & \multicolumn{1}{|c|}{ Condiciones } \\
\hline $\mathbf{1}$ & $\begin{array}{l}\text { Toda la información considerada en la definición del indicador y } \\
\text { cumplimiento de las condiciones básicas de accesibilidad }\end{array}$ \\
\hline $\mathbf{0 , 5}$ & $\begin{array}{l}\text { Información parcial pero cumplimiento de las condiciones básicas de } \\
\text { accesibilidad }\end{array}$ \\
\hline $\mathbf{0}$ & $\begin{array}{l}\text { No se dispone en absoluto o mínimamente de la información } \\
\text { correspondiente al indicador }\end{array}$ \\
\hline \multicolumn{1}{|c}{ Fuente: Elaboración propia } \\
\hline
\end{tabular}

Las condiciones de accesibilidad de la información que debe cumplimentar el diseño de cada sitio web en sus diferentes puntos para obtener la valoración positiva están dadas por dos criterios base: la información debe estar actualizada y debe ser fácilmente localizable, de manera que resulte accesible para la ciudadanía en su conjunto, no debiendo disponer de un conocimiento más allá del básico para poder disponer de los datos. Cabe destacar que -siguiendo la metodología original- no se validará con la puntuación máxima un indicador si la información no está bien nombrada y direccionada desde el menú de la página web principal.

Una vez asignados los valores para cada uno de los 52 indicadores (0; 0,5 ó 1) para los municipios considerados, cada municipio recibe una puntuación de acuerdo con el número de indicadores valuados positivamente. Asimismo, se crea un nuevo indicador resumen para cada una de las localidades, aproximando el estado de transparencia asociado a la información disponible en los sitios web. Este indicador permite comparar la posición relativa de cada gobierno subnacional respecto de las otras administraciones, posibilitando posicionar cada localidad de acuerdo a la media general de los municipios o bien respecto al promedio correspondiente a 
localidades de similar tamaño o características, incentivando mejoras en la materia de transparencia.

El análisis se realizó para un total de 70 gobiernos subnacionales, correspondientes a los tres municipios más importantes (en materia poblacional) de cada una de las 23 provincias del país, y la Ciudad Autónoma de Buenos Aires, que representan el $24 \%$ de la población nacional, según lo establece el último Censo Nacional (2010). Con esta muestra de localidades, se espera tener un conocimiento más acabado de la situación local, en materia de transparencia y difusión de la información para una mejor interacción con la ciudadanía.

Además de obtener información sobre el nivel de transparencia de cada municipio sumando los valores totales obtenidos y por categoría; también se construyó un índice (del o al 100) tomando como base, para cada categoría, la máxima distancia observada entre el mejor desempeño observado en cada eje y los valores de cada municipio. Como se ilustra en el siguiente esquema, se asignó el valor 100 a los municipios con menor grado de transparencia (color rojo) y o a las localidades mejor ponderadas (color verde). En el caso de los resultados provinciales, se realizó el promedio simple de los 52 indicadores observados para las 3 jurisdicciones seleccionadas por provincia (según el criterio poblacional) a fin de realizar el cálculo del indice general.

\section{Esquema 2: Índice de transparencia en base a la distancia respecto al mejor desempeño}

$\begin{array}{lr}0 & 100 \\ \text { Mejor desempeño } & \text { Peor desempeño } \\ \text { Más transparentes } & \text { Menos transparentes }\end{array}$

No fueron consideradas otras variables como el sexo del intendente lo cual representa una falencia al considerar que en los estudios realizados en España o Ecuador existe evidencia que aquellas localidades lideradas por una mujer suelen ser más transparentes que aquellos liderados por hombres. $Y$ tampoco fue considerado el partido político al que pertenece el intendente de la localidad. 


\section{Resultados}

Se presentan a continuación los resultados obtenidos para 70 municipios argentinos, los tres municipios más importantes en materia poblacional de cada una de las provincias de la República Argentina, y la Ciudad Autónoma de Buenos Aires para el año 2019 y 2020.

\subsection{Diagnóstico de principales municipios - Año 2019}

En primera instancia, los resultados evidenciaron para todas las localidades analizadas, un nivel de transparencia medio-bajo alcanzando los municipios mejor valorados (Godoy Cruz en Mendoza, ciudad de Córdoba y Ciudad Autónoma de Buenos Aires) un total de entre 39,5 y 37 puntos sobre un total de 52.

Para el caso del primer eje (Autoridades), un 4\% de los municipios alcanzó un nivel mayor al 75\% entre los que se destacan los municipios de Córdoba, Godoy Cruz (Mendoza) y la ciudad de Santa Fe, con puntuaciones de 8 sobre 11 indicadores relevados.

\section{Gráfico 3: Porcentaje de municipios según nivel de cumplimiento del Eje Autoridades - Año 2019}

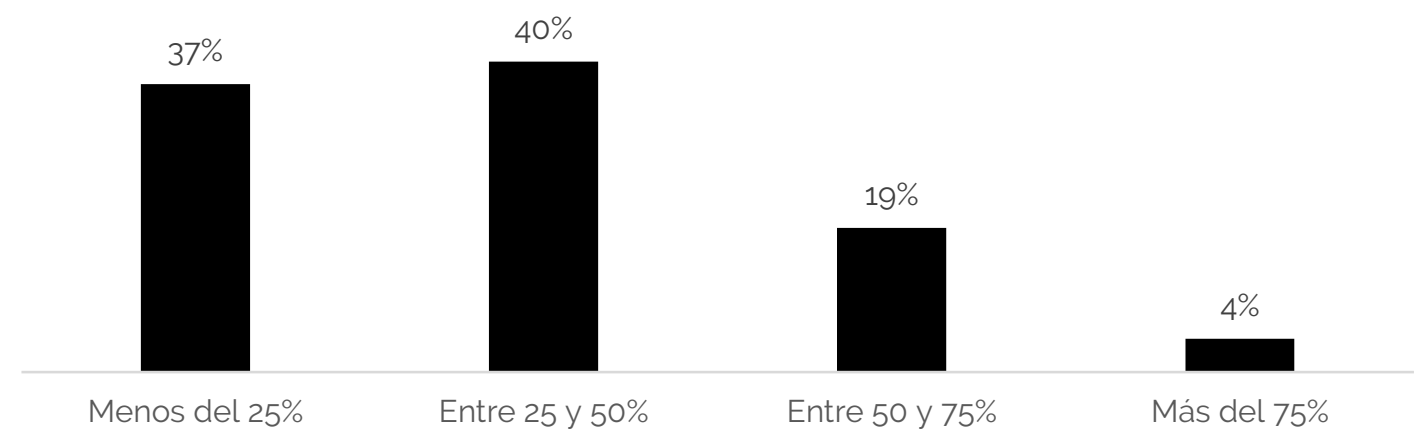

Fuente: Elaboración propia

Para la categoría de Órganos de gobierno, se incrementa respecto de la categoría anterior el porcentaje de municipios que no alcanzan más del $25 \%$ del nivel de transparencia. No obstante, aumenta también el porcentaje de municipios que logran un nivel mayor al 75\% en esta categoria. 


\section{Gráfico 4: Porcentaje de municipios según nivel de cumplimiento \\ del Eje Órganos de gobierno - Año 2019}

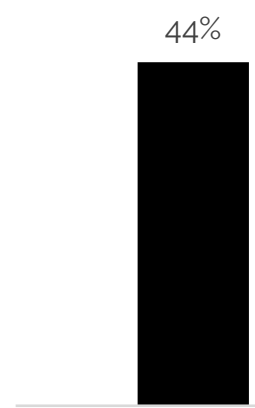

Menos del $25 \%$

Fuente: Elaboración propia

En el caso del eje de Rendición de cuentas, se observa un mejor desempeño comparado con los ejes anteriores puesto que 33\% de los municipios obtuvo un nivel por encima del $75 \%$. Sumado al porcentaje de municipios que alcanzaron un nivel entre el 50 y $75 \%$, el porcentaje de municipios que alcanzaron un nivel superior al $50 \%$, representa el $46 \%$ del total de municipios.

\section{Gráfico 5: Porcentaje de municipios según nivel de cumplimiento del Eje Rendición de Cuentas - Año 2019}

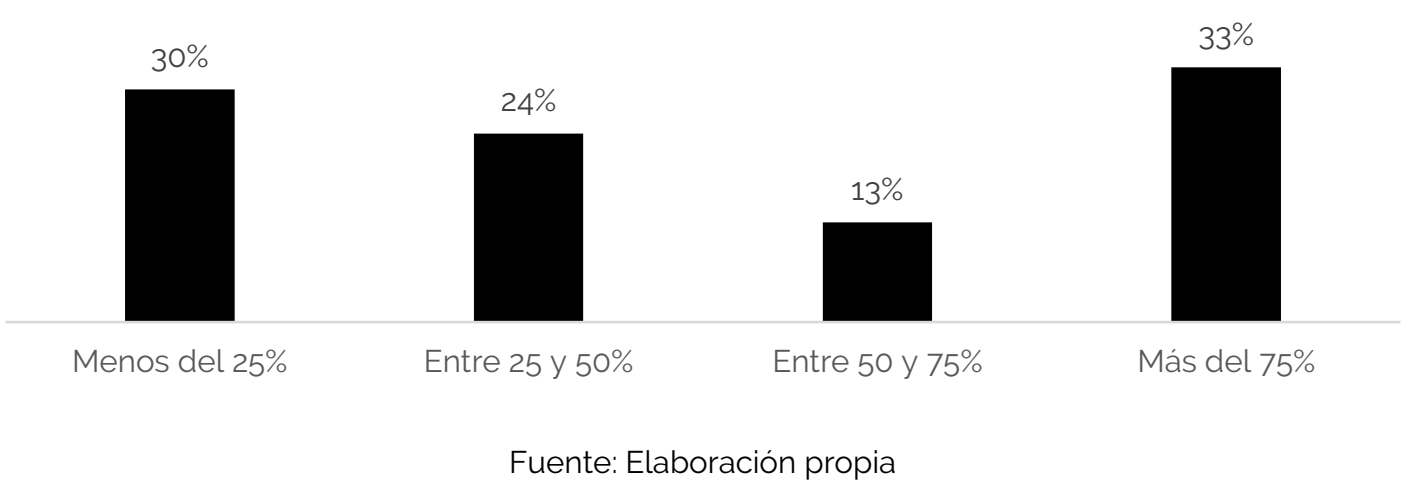

Respecto de la rendición presupuestaria, aqui se observa el peor desempeño por parte de los municipios ya que el $87 \%$ de ellos no alcanzó más del 50\% del valor esperado para este eje. No obstante, existió un 3\% que logró un valor por encima del $75 \%$, destacándose los municipios de Concordia y Gualeguaychú (Entre Ríos) seguidos por la localidad de Mar del Plata (Buenos Aires). 


\section{Gráfico 6: Porcentaje de municipios según nivel de cumplimiento del Eje Presupuesto - Año 2019}

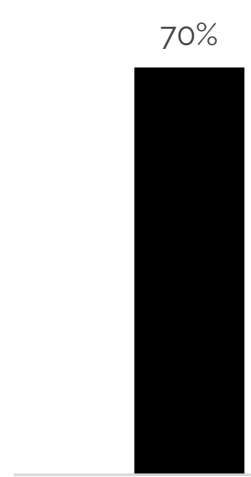

Menos del 25\%

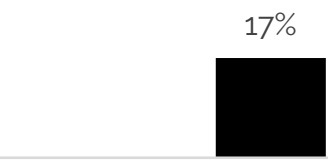

Entre 25 y $50 \%$

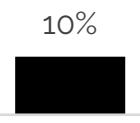

Entre 50 y $75 \%$
$3 \%$

Más del $75 \%$

Fuente: Elaboración propia

Para el eje referido a Contratos y licitaciones públicas, también el desempeño fue muy bajo puesto que el $80 \%$ de los municipios obtuvo un valor menor al $25 \%$ del esperado y ningún municipio logró un nivel por encima del $75 \%$.

\section{Gráfico 7: Porcentaje de municipios según nivel de cumplimiento del Eje Contrato y licitaciones - Año 2019}

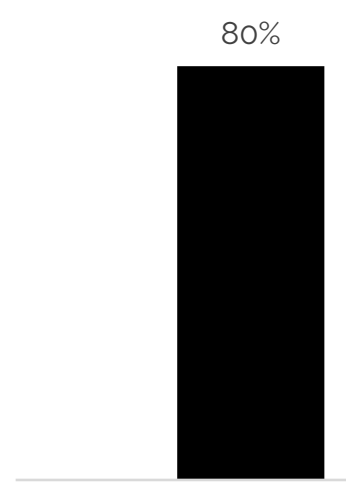

Menos del 25\%

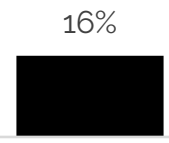

Entre 25 y $50 \%$
$4 \%$

Entre 50 y $75 \%$

Fuente: Elaboración propia

El 79\% de los municipios presentó un nivel de transparencia por debajo del 50\% en lo referido a Comunicación Institucional y sólo un 21\% de los municipios alcanzó un nivel por encima del 50\%. Este eje refiere a la publicidad de información sobre las actuaciones de los miembros del gobierno y de la oposición relacionadas con el control de la gestión del gobierno, sobre las sesiones del Concejo Deliberante, los costos de la publicidad institucional y los nombres de las empresas o personas que 
han incumplido contratos. Por lo tanto, un bajo nivel de cumplimiento en este eje requiere especial atención.

\section{Gráfico 8: Porcentaje de municipios según nivel de cumplimiento del Eje Comunicación Institucional - Año 2019}

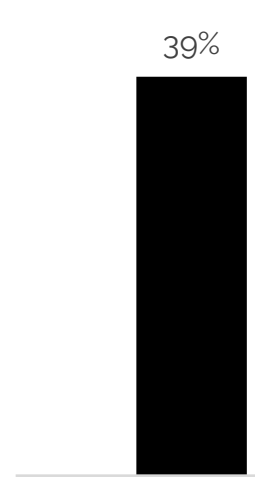

Menos del 25\%

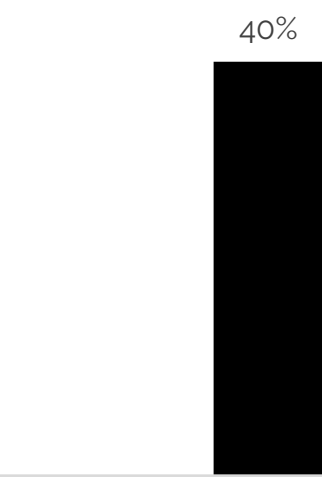

Entre 25 y $50 \%$

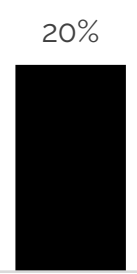

Entre 50 y $75 \%$

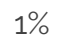

Más del $75 \%$

Fuente: Elaboración propia

Del total de localidades consideradas, 38 de ellas (56\%) presentaron la calificación máxima en el eje correspondiente a la información general, siendo éste uno de los primeros aspectos contemplados en los planes de modernización subnacional. No se encontró ningún municipio con un nivel por debajo del $25 \%$ del valor esperado y éste fue el eje donde mayor porcentaje de municipios superaron el 50\% (93\% de los municipios).

\section{Gráfico 9: Porcentaje de municipios según nivel de cumplimiento del Eje Información General - Año 2019}

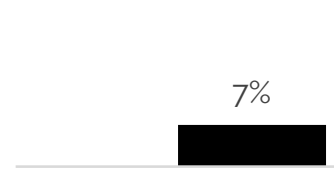

Entre el 25 y $50 \%$

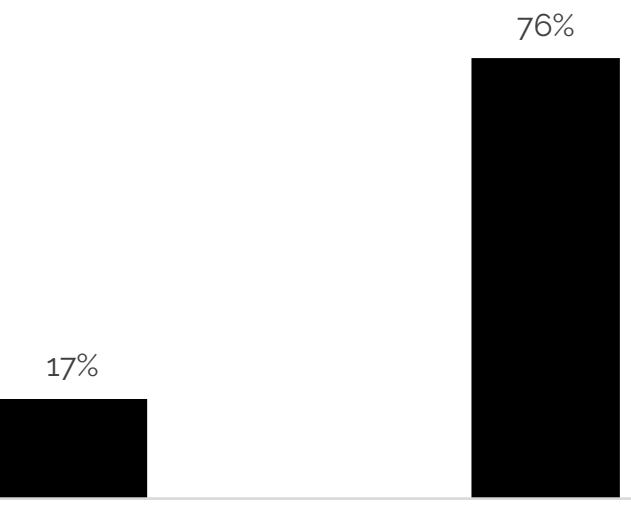

Entre el 50 y $75 \%$

Más del $75 \%$

Fuente: Elaboración propia 
Se detectaron cuatro municipios que no poseen ningún mecanismo legítimo de participación ciudadana (o si tienen el acceso en la web, el vínculo se encuentra fuera de funcionamiento o en periodo de prueba), mientras el 66\% de los municipios no alcanzaron a cubrir el $50 \%$ de los requerimientos mínimos sugeridos por la metodología.

\section{Gráfico 10: Porcentaje de municipios según nivel de cumplimiento del Eje Participación Ciudadana - Año 2019}

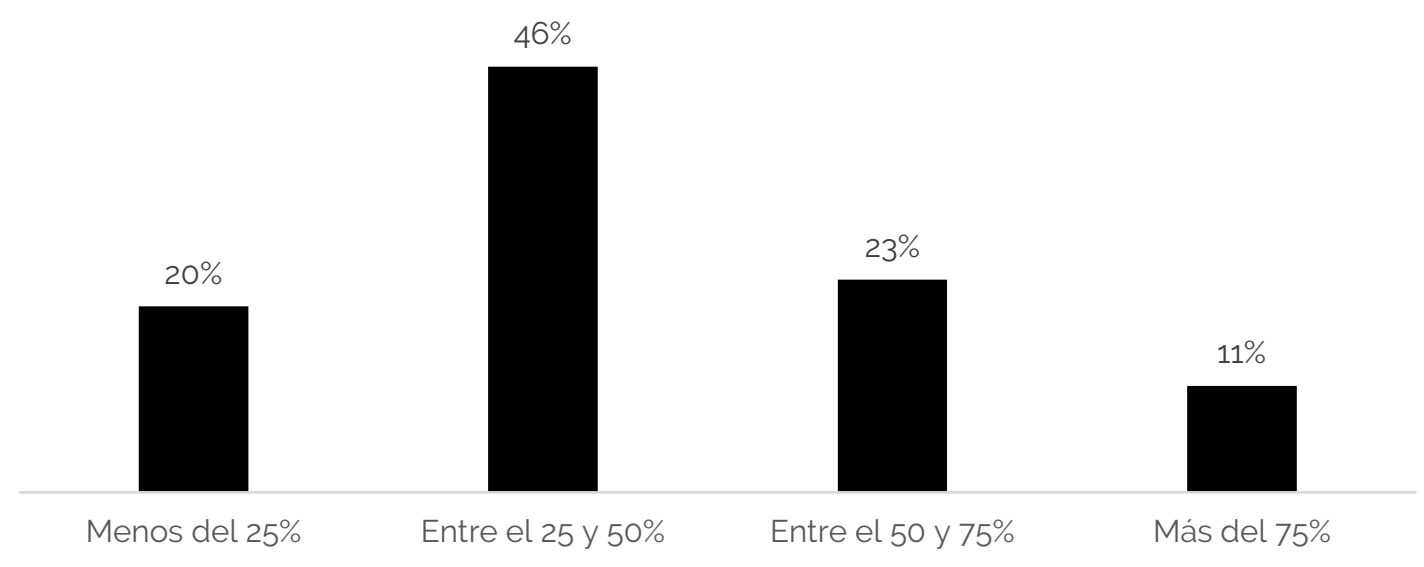

Fuente: Elaboración propia

Para poder realizar un diagnóstico más ajustado de la realidad local, se realizó la comparación de la puntuación total obtenida por cada municipio con el máximo valor observado y se efectuó una normalización de esa información para dotarlo de mayor representatividad. De esta manera, se calculan las 'distancias' existentes entre la puntuación obtenida por cada localidad y el mejor desempeño a nivel local. Se toma como indicador base la falta de transparencia (considerada como la distancia de cada indicador al mejor resultado observado), siendo 100 el peor desempeño posible y o el mejor.

El mejor desempeño correspondió al municipio de Godoy Cruz de la provincia de Mendoza seguido por la ciudad de Córdoba (provincia homónima), municipio de Concordia (Entre Ríos), Mar del Plata (Buenos Aires) y ciudad de Santa Fe (provincia homónima). Mientras que los peores desempeños corresponden a los municipios de Guaymallen (Mendoza), Merlo (San Luis), San Martín (Catamarca), Río Truncado (Santa Cruz) y La Banda (Santiago del Estero). 
Tabla 7:Ranking de municipios de acuerdo al nivel de transparencia obtenido.

Peor valuación = 100. Año 2019

\begin{tabular}{|c|c|c|c|}
\hline Posición & Principales Municipios & Provincia & Índice \\
\hline 1 & Godoy Cruz & Mendoza & 0,0 \\
\hline 2 & Ciudad de Córdoba & Córdoba & 4,2 \\
\hline 3 & Concordia & Entre Ríos & 11,1 \\
\hline 4 & Mar del Plata & Buenos Aires & 16.7 \\
\hline 5 & Ciudad de Santa Fe & Santa Fe & 26,4 \\
\hline 6 & Gualeguaychú & Entre Ríos & 27,8 \\
\hline 7 & Río Cuarto & Córdoba & 30,6 \\
\hline 8 & Rafaela & Santa Fe & 30,6 \\
\hline 9 & La Plata & Buenos Aires & 34.7 \\
\hline 10 & Trelew & Chubut & 36,1 \\
\hline 11 & Ciudad de Neuquén & Neuquén & 37.5 \\
\hline 12 & Ciudad de San Juan & San Juan & 37.5 \\
\hline 13 & Ciudad de San Luis & San Luis & 37.5 \\
\hline 14 & Buenos Aires & CABA & 40,3 \\
\hline 15 & Santa Rosa & La Pampa & 40,3 \\
\hline 16 & Ciudad de Salta & Salta & 40,3 \\
\hline 17 & Eldorado & Misiones & 41,7 \\
\hline 18 & Lanús & Buenos Aires & 43,1 \\
\hline 19 & Resistencia & Chaco & 43,1 \\
\hline 20 & General Pico & La Pampa & 43,1 \\
\hline 21 & Goya & Corrientes & 44,4 \\
\hline 22 & Palpalá & Jujuy & 44,4 \\
\hline 23 & Corrientes & Corrientes & 45,8 \\
\hline 24 & Villa Mercedes & San Luis & 45,8 \\
\hline 25 & Villa Maria & Córdoba & 50,0 \\
\hline 26 & Posadas & Misiones & 51,4 \\
\hline 27 & Barranqueras & Chaco & 52,8 \\
\hline 28 & Viedma & Rio Negro & 52,8 \\
\hline 29 & Oberá & Misiones & 59,7 \\
\hline 30 & Puerto Madryn & Chubut & 61,1 \\
\hline 31 & Cutral-co & Neuquén & 61,1 \\
\hline 32 & Paraná & Entre Ríos & 62,5 \\
\hline 33 & San Salvador de Jujuy & Jujuy & 62,5 \\
\hline 34 & Ciudad de La Rioja & La Rioja & 62,5 \\
\hline 35 & San Carlos de Bariloche & Rio Negro & 63.9 \\
\hline
\end{tabular}


Tabla 8: Ranking de municipios de acuerdo al nivel de transparencia obtenido.

Peor valuación = 100. Año 2019 (Continuación)

\begin{tabular}{|c|c|c|c|}
\hline Posición & Principales Municipios & Provincia & Índice \\
\hline 36 & Comodoro Rivadavia & Chubut & 65.3 \\
\hline 37 & Ciudad de Formosa & Formosa & 66.7 \\
\hline 38 & Ushuaia & Tierra del Fuego & 66.7 \\
\hline 39 & Chilecito & La Rioja & 68,1 \\
\hline 40 & Presidencia Roque Sáenz Peña & Chaco & 69,4 \\
\hline 41 & Río Gallegos & Santa Cruz & 69,4 \\
\hline 42 & Yerba Buena & Tucumán & 69,4 \\
\hline 43 & San Pedro de Jujuy & Jujuy & 70,8 \\
\hline 44 & Rosario & Santa Fe & 70,8 \\
\hline 45 & $\begin{array}{l}\text { San Fernando del Valle de } \\
\text { Catamarca }\end{array}$ & Catamarca & 72,2 \\
\hline 46 & General Roca & Rio Negro & 72,2 \\
\hline 47 & San Miguel de Tucumán & Tucumán & 72,2 \\
\hline 48 & Tartagal & Salta & 73,6 \\
\hline 49 & Rivadavia & San Juan & 75,0 \\
\hline 50 & Rawson & San Juan & 75,0 \\
\hline 51 & Caleta Olivia & Santa Cruz & 75,0 \\
\hline 52 & Rio Grande & Tierra del Fuego & 75,0 \\
\hline 53 & Las Heras & Mendoza & 76,4 \\
\hline 54 & Banda del Río Salí & Tucumán & 76,4 \\
\hline 55 & Paso de los Libres & Corrientes & 77,8 \\
\hline 56 & Clorinda & Formosa & 77,8 \\
\hline 57 & Pirané & Formosa & 77,8 \\
\hline 58 & San Ramón de la Nueva Orán & Salta & 77,8 \\
\hline 59 & Ciudad de Santiago del Estero & Santiago del Estero & 80,6 \\
\hline 60 & General Acha & La Pampa & 81,9 \\
\hline 61 & Tolhuin & Tierra del Fuego & 81,9 \\
\hline 62 & Arauco & La Rioja & 83.3 \\
\hline 63 & Centenario & Neuquén & 83.3 \\
\hline 64 & Termas de Río Hondo & Santiago del Estero & 84.7 \\
\hline 65 & Valle Viejo & Catamarca & 86,1 \\
\hline 66 & Guaymallén & Mendoza & 86,1 \\
\hline 67 & Merlo & San Luis & 86,1 \\
\hline 68 & Santa María & Catamarca & 88,9 \\
\hline 69 & Pico Truncado & Santa Cruz & 88,9 \\
\hline 70 & La Banda & Santiago del Estero & 94,4 \\
\hline
\end{tabular}

Fuente: Elaboración propia 
Al realizar una comparación en el contexto geográfico del país, se puede elaborar un índice tomando como límite superior en la escala, el máximo observado por alguno de los municipios en consideración, y calcular cuál es la distancia que existe entre la realidad de cada localidad y la situación más favorable dentro del país. Puede observarse que los mejores niveles de transparencia se encuentran mayoritariamente en la Región Pampeana (con excepción de la provincia de La Pampa, que se encuentra en el segundo grupo entre las provincias menos transparentes).

\section{Mapa 1: Diagnóstico provincial promedio. Índice general. Año 2019}

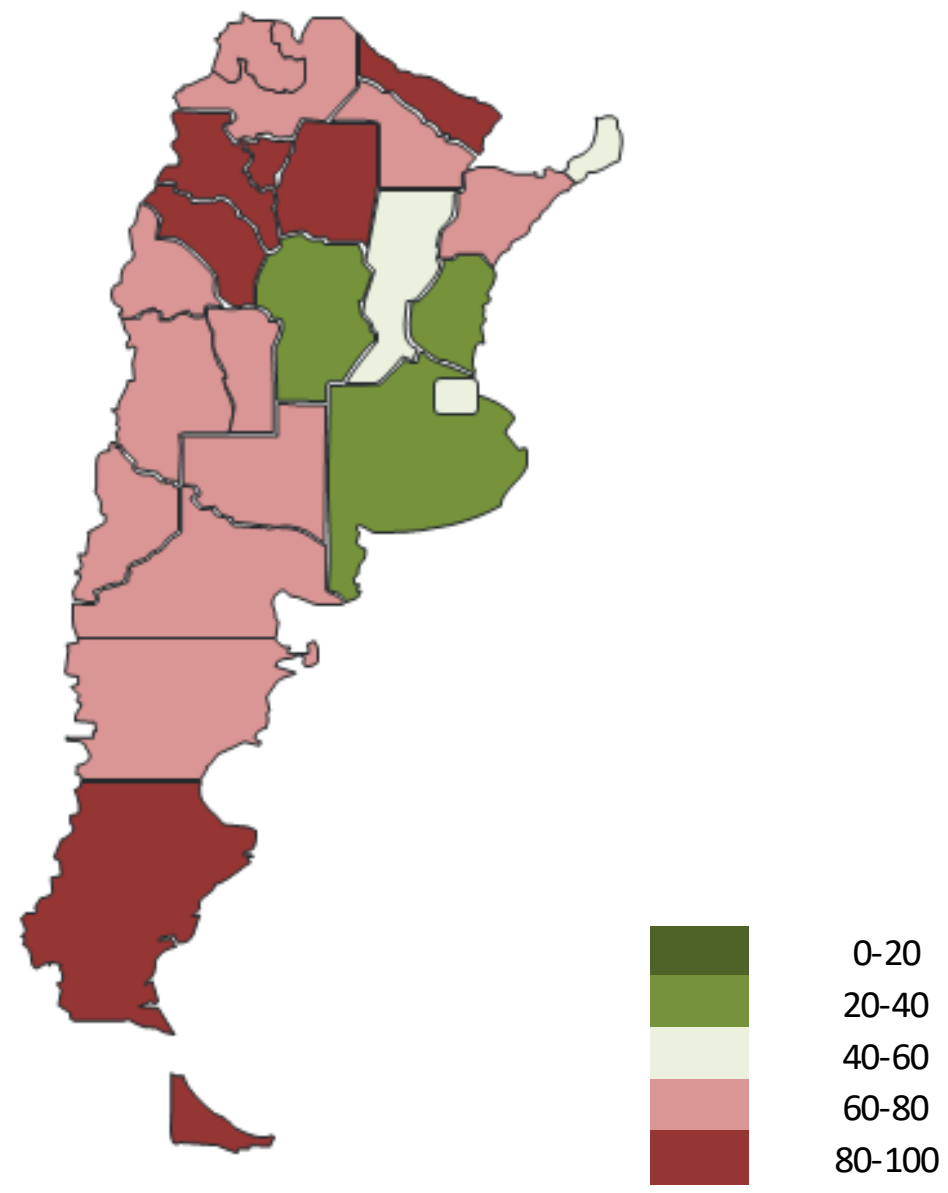

Fuente: Elaboración propia

Los menores niveles de transparencia se dan en los municipios de las dos provincias más al sur en la Patagonia (Santa Cruz y Tierra del Fuego), y en cuatro de las seis provincias que conforman el Noroeste Argentino (NOA), a saber: La Rioja, Catamarca, Tucumán y Santiago del Estero. También exhiben muy baja transparencia los municipios de la provincia de Formosa, en el Noroeste Argentino (NEA).

A nivel jurisdiccional, se destacan favorablemente los municipios de las provincias de Buenos Aires, Córdoba y Entre Ríos, por tener en todos los criterios, una 
valoración positiva, siendo donde se ubican las localidades mejor posicionadas, a las que siguen la Ciudad Autónoma de Buenos Aires (CABA), y las provincias de Santa Fe y Misiones, con un desempeño medio-alto. En el extremo opuesto, llama la atención la situación de la provincia de Santiago del Estero, que se ubica a la máxima distancia posible del máximo observado en el 50\% de los indicadores analizados, y en el resto de ellos la calificación obtenida también se torna desfavorable. Le sigue la provincia de Catamarca, con todos sus indicadores en baja perfomance.

\section{Tabla 9:Diagnóstico provincial, por categoría. Peor valuación = 100. Año 2019}

\begin{tabular}{|c|c|c|c|c|c|c|c|c|c|}
\hline Provincia & Autoridades & $\begin{array}{c}\text { Órganos de } \\
\text { gobierno }\end{array}$ & $\begin{array}{l}\text { Rendición } \\
\text { de cuentas }\end{array}$ & Presupuesto & $\begin{array}{l}\text { Contrataciones } \\
\text { ylicitaciones }\end{array}$ & $\begin{array}{l}\text { Comunicación } \\
\text { institucional }\end{array}$ & $\begin{array}{l}\text { Información } \\
\text { general }\end{array}$ & $\begin{array}{c}\text { Participación } \\
\text { ciudadana }\end{array}$ & TOTAL \\
\hline Buenos Aires & 36 & 0 & 0 & 21 & 14 & 11 & 0 & 0 & 30 \\
\hline CABA & 44 & 60 & 55 & 37 & 52 & 0 & 56 & 57 & 0 \\
\hline Catamarca & 74 & 90 & 90 & 79 & 100 & 78 & 88 & 100 & 99 \\
\hline Chaco & 41 & 55 & 35 & 84 & 76 & 100 & 13 & 48 & 67 \\
\hline Chubut & 44 & 30 & 35 & 89 & 76 & 22 & 31 & 19 & 60 \\
\hline Córdoba & 0 & 10 & 25 & 47 & 0 & 0 & 0 & 0 & 27 \\
\hline Corrientes & 51 & 25 & 60 & 89 & 90 & 56 & 13 & 43 & 68 \\
\hline Entre Ríos & 44 & 20 & 15 & 0 & 29 & 11 & 13 & 0 & 35 \\
\hline Formosa & 85 & 100 & 60 & 100 & 100 & 44 & 63 & 52 & 91 \\
\hline Jujuy & 56 & 75 & 60 & 95 & 90 & 89 & 13 & 0 & 72 \\
\hline La Pampa & 74 & 20 & 50 & 89 & 81 & 11 & 25 & 33 & 68 \\
\hline La Rioja & 74 & 70 & 100 & 100 & 100 & 100 & 13 & 67 & 90 \\
\hline Mendoza & 38 & 40 & 60 & 74 & 24 & 33 & 50 & 33 & 59 \\
\hline Misiones & 44 & 40 & 15 & 58 & 86 & 22 & 0 & 52 & 57 \\
\hline Neuquén & 67 & 35 & 75 & 68 & 81 & 78 & 0 & 52 & 72 \\
\hline Rio Negro & 51 & 45 & 55 & 63 & 67 & 33 & 0 & 67 & 65 \\
\hline Salta & 67 & 55 & 70 & 58 & 90 & 44 & 13 & 62 & 74 \\
\hline San Juan & 64 & 50 & 75 & 68 & 81 & 56 & 25 & 76 & 77 \\
\hline San Luis & 67 & 55 & 35 & 89 & 52 & 44 & 25 & 43 & 68 \\
\hline Santa Cruz & 87 & 75 & 80 & 95 & 90 & 78 & 25 & 76 & 91 \\
\hline Santa Fe & 13 & 5 & 10 & 37 & 0 & 67 & 38 & 14 & 33 \\
\hline $\begin{array}{l}\text { Santiago del } \\
\text { Estero }\end{array}$ & 100 & 80 & 75 & 79 & 95 & 100 & 100 & 71 & 100 \\
\hline $\begin{array}{l}\text { Tierra del } \\
\text { Fuego }\end{array}$ & 87 & 65 & 55 & 37 & 52 & 44 & 38 & 57 & 73 \\
\hline Tucumán & 67 & 75 & 80 & 100 & 81 & 33 & 56 & 90 & 88 \\
\hline
\end{tabular}

Fuente: Elaboración propia

Los indicadores referidos a las autoridades, órganos de gobierno, rendición de cuentas e información general, son los que presentaron una mejor performance en los gobiernos locales, mientras que, en materia de contratos y licitaciones públicas, rendición presupuestaria y participación ciudadana, se perciben la mayor cantidad de posibilidades de mejora. 


\subsection{Diagnóstico de principales municipios- Año 2020}

En el relevamiento correspondiente al año 2020, se observan resultados similares a los del año anterior. Para todas las localidades analizadas, el nivel de transparencia alcanzado es medio-bajo. Tal es así que, aun los municipios mejor valorados no alcanzan a cubrir tres cuartas partes de los indicadores propuestos en la metodología original. Si se analiza la performance por categoria, en el Eje Autoridades el mayor porcentaje de municipios de los relevados se encuentra en un nivel de transparencia por debajo del 50\% (83\%) y 17\% de los municipios alcanza a superar ese umbral.

\section{Gráfico 11: Porcentaje de municipios según nivel de cumplimiento del Eje Autoridades - Año 2020}

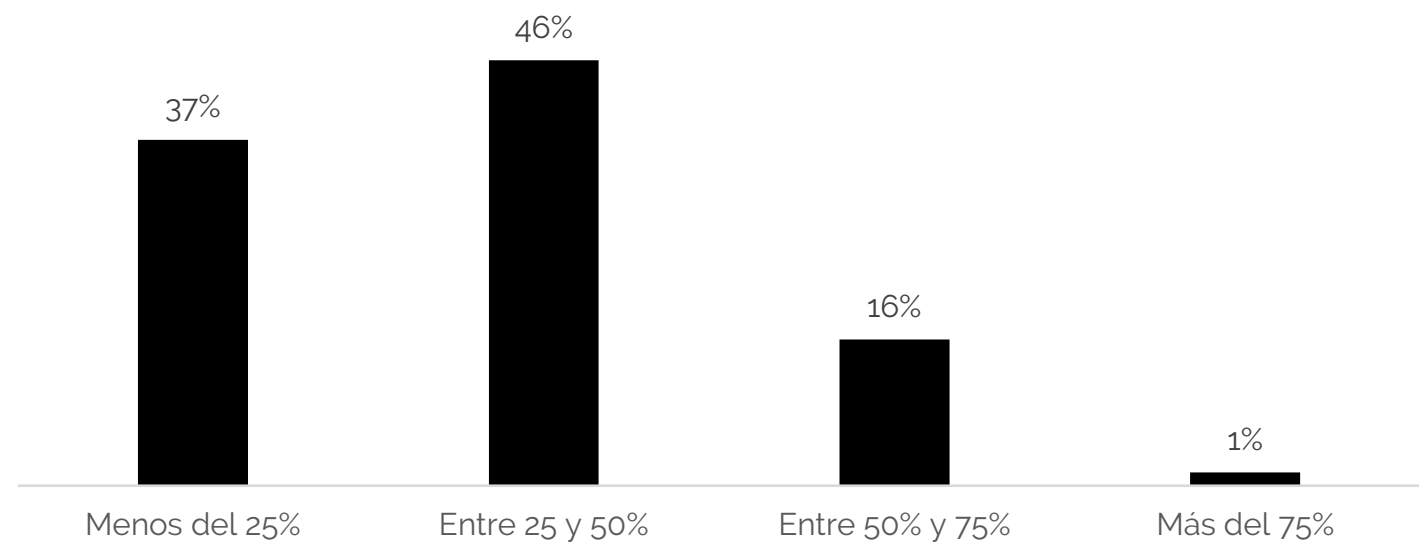

Fuente: Elaboración propia

En lo que respecta al segundo eje (Órganos de gobierno) los valores mejoran si se los compara con el eje anterior ya que aproximadamente el $40 \%$ de los municipios logra valores positivos en más del $50 \%$ de los indicadores de este eje y dentro de éstos un 13\% logra buenos valores en más del 75\%. Dentro de este último grupo se encuentran los municipios de Santa Rosa (La Pampa) con puntaje perfecto, seguida por Ciudad de Córdoba, Mar del Plata, Paraná y San Carlos de Bariloche. 


\section{Gráfico 12: Porcentaje de municipios según nivel de cumplimiento \\ del Eje Órganos de gobierno - Año 2020}

Menos del 25\%

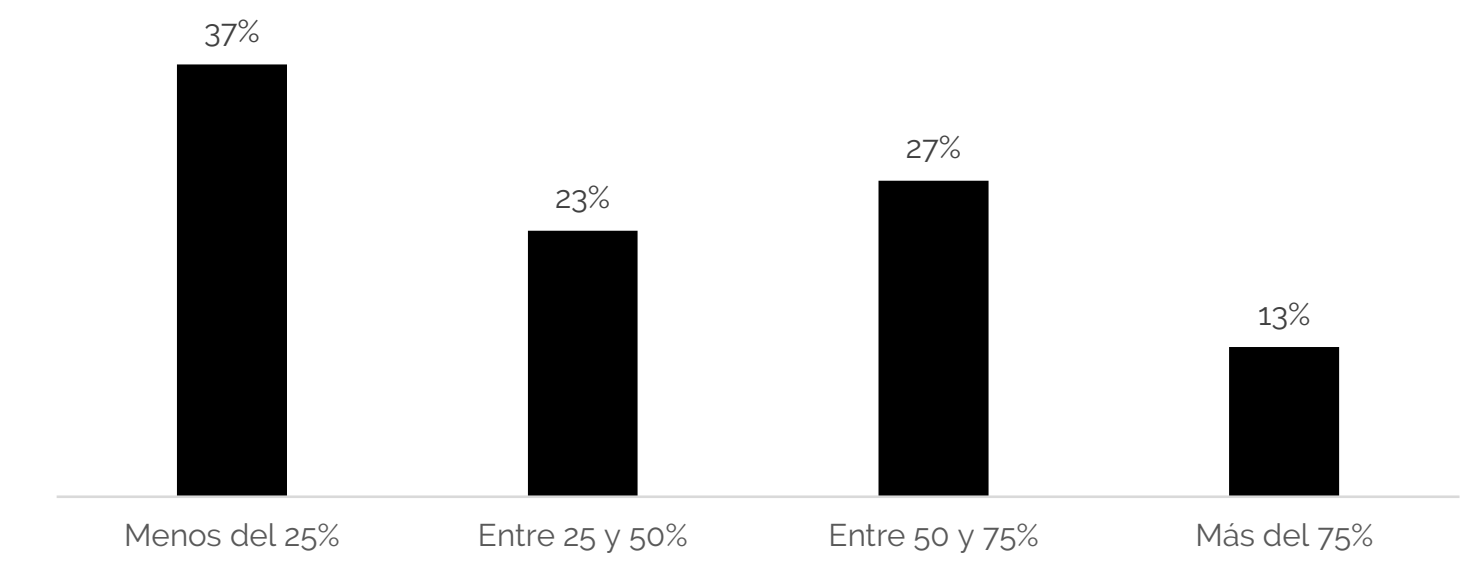

Fuente: Elaboración propia

Para el caso de Rendición de Cuentas, el mejor puntaje lo obtuvo la Ciudad Autónoma de Buenos Aires con 3.5 puntos sobre 4. Mientras que el 59\% de los municipios no llegó a cumplimentar la mitad de los requisitos evaluados en este eje.

\section{Gráfico 13: Porcentaje de municipios según nivel de cumplimiento del Eje Rendición de Cuentas}
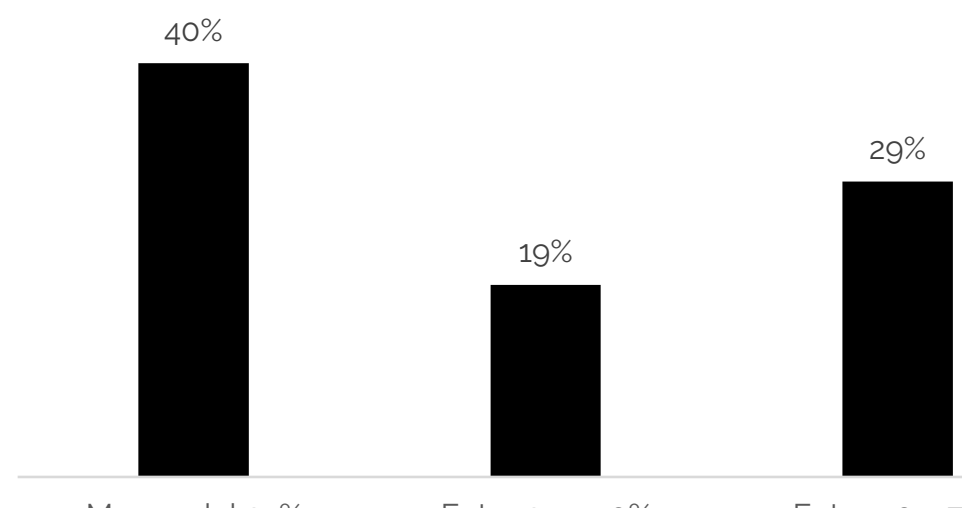

Menos del 25\%

Entre 25 y $50 \%$

Entre 50 y $75 \%$

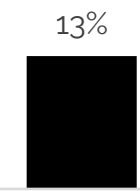

Más del $75 \%$

Fuente: Elaboración propia

Respecto de la rendición presupuestaria, que incluye la presentación del presupuesto actual, los presupuestos anteriores, todas las modificaciones realizadas, los indicadores de sostenibilidad financiera, las relaciones presupuestarias respecto de los puestos de trabajo, sobresale Concordia (Entre Ríos) único municipio que alcanzó puntaje perfecto (6). A esta, le siguen en orden de importancia la Ciudad Autónoma de Buenos Aires (5,5), Mar del Plata (Buenos Aires) y Las Heras (Mendoza), ambas con 5 puntos. Del total de 70 municipios, 32 no 
alcanzaron a cumplimentar ninguno de los instrumentos evaluados, siendo este eje con mayor cantidad de valores nulos. Esto se observa en el gráfico donde se representa que el $73 \%$ de los municipios no alcanzó a cumplir más del $25 \%$ de los indicadores correspondientes a esta categoria.

\section{Gráfico 14: Porcentaje de municipios según nivel de cumplimiento del Eje Presupuesto}
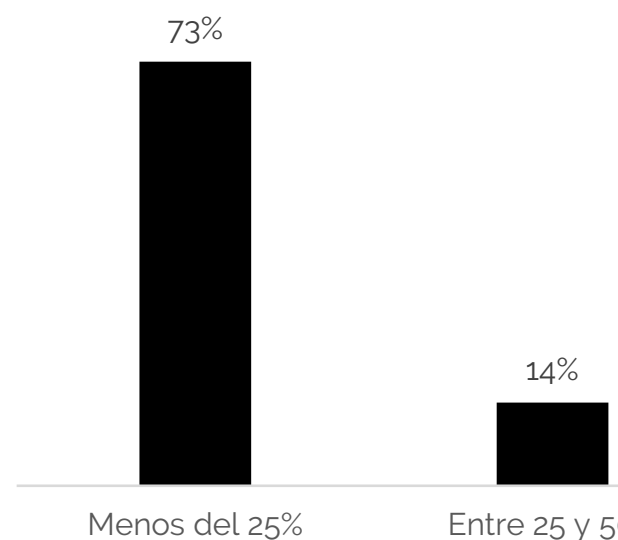

Entre 25 y $50 \%$

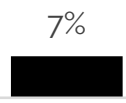

$6 \%$

Entre 50 y $75 \%$

Más del $75 \%$

Fuente: Elaboración propia

Entre tanto, en lo que respecta a contrataciones y licitaciones los resultados tampoco fueron los mejores considerando que el valor promedio total fue de 1,1 puntos sobre 10. En este caso, 29 municipios tuvieron puntaje igual a 0 al no presentar ninguno de los instrumentos contemplados en este eje. El total de los municipios obtuvo valores por debajo del $50 \%$ del total de este eje y ninguno alcanzo cumplir más del $50 \%$ de los requerimientos.

\section{Gráfico 15: Porcentaje de municipios según nivel de cumplimiento del Eje Compras y licitaciones}

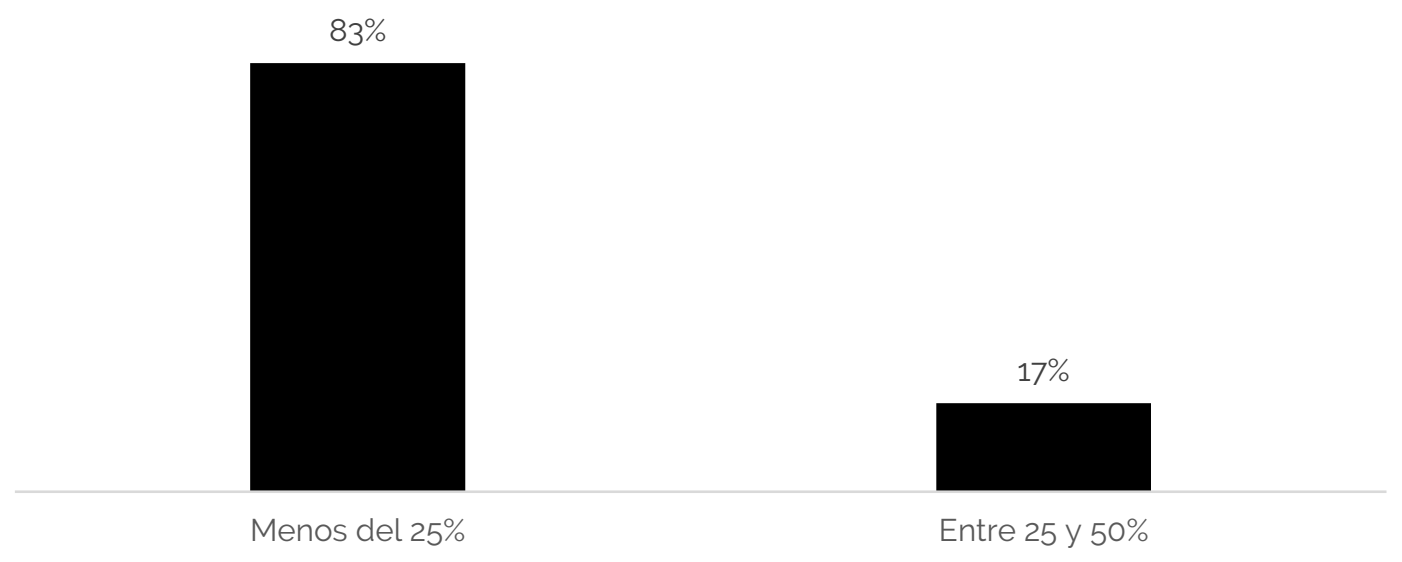


En lo que refiere a Comunicación Institucional la Ciudad Autónoma de Buenos Aires y Comodoro Rivadavia (Chubut) fueron los municipios con mejores puntajes con 4.5 y 4, respectivamente; mientras que más del 50\% de los municipios relevados obtuvo una puntuación menor a 2 puntos sobre un óptimo de 5 . Sólo el 10\% de los municipios relevados alcanzó cumplimentar más del 50\% de los aspectos observados en este eje.

\section{Gráfico 16: Porcentaje de municipios según nivel de cumplimiento del Eje Comunicación institucional}

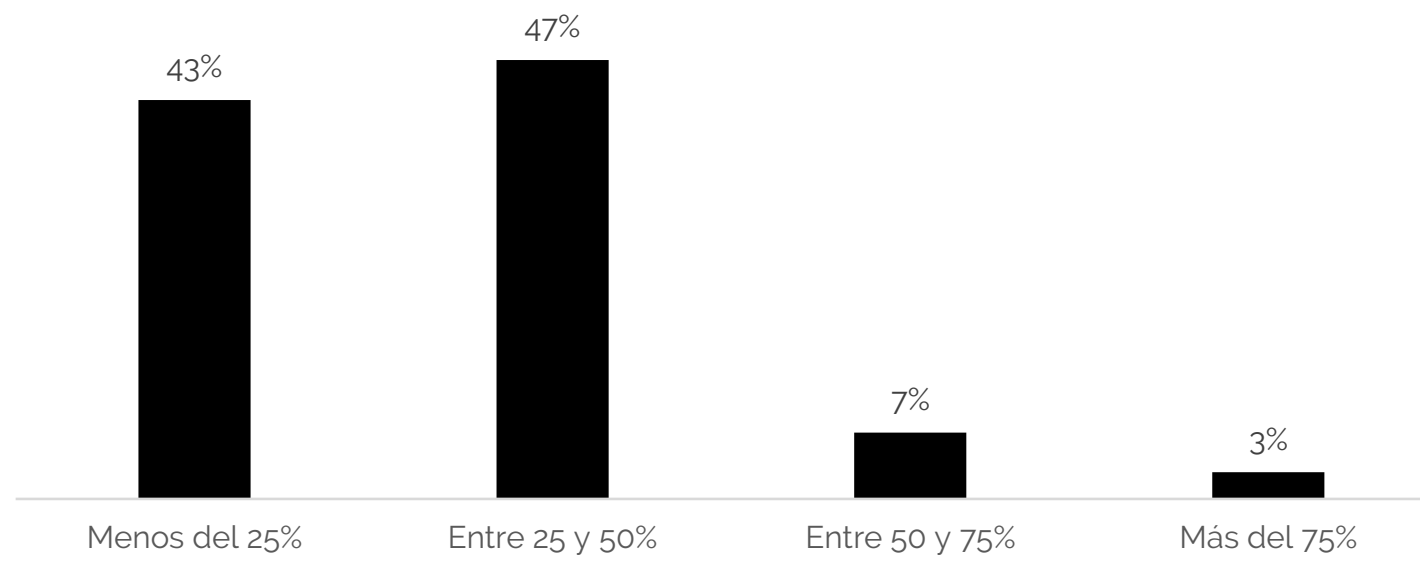

Fuente: Elaboración propia

En información general aparece nuevamente la Ciudad Autónoma de Buenos Aires con puntaje perfecto (4) secundada por la Ciudad de Córdoba (3.5) frente a un promedio bajo a nivel general de 1,4. El mayor porcentaje de municipios se encontró entre el 25 y $50 \%$ de cumplimiento.

\section{Gráfico 17: Porcentaje de municipios según nivel de cumplimiento del Eje Información General}

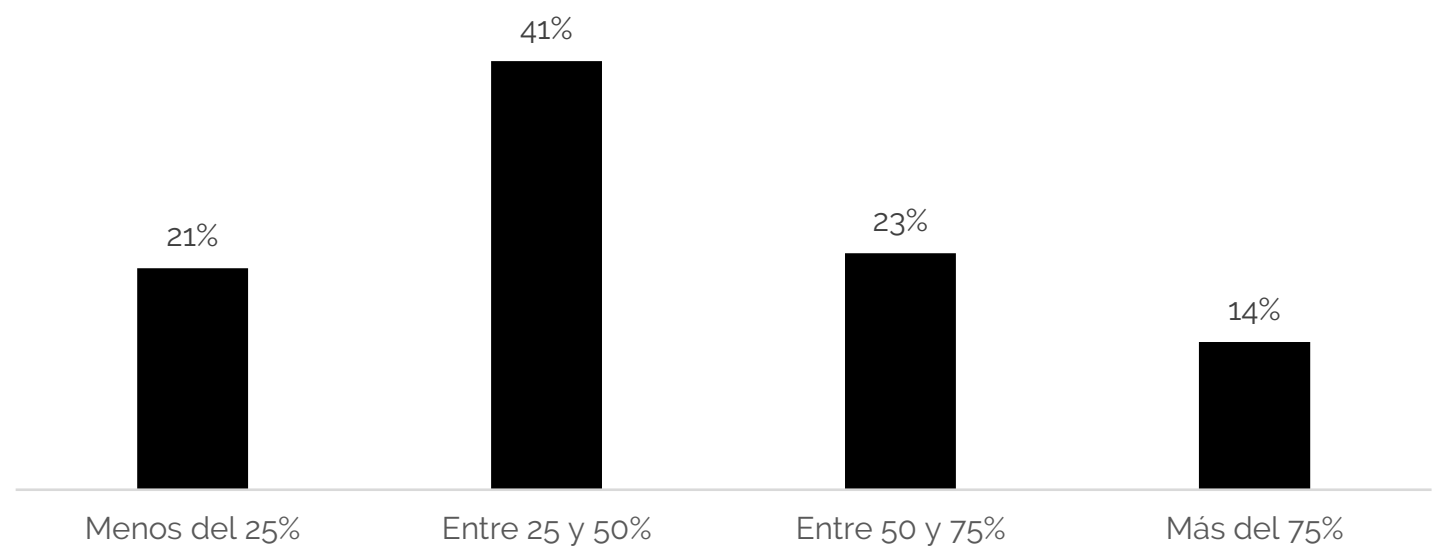


En Participación Ciudadana sólo el $16 \%$ superó la mitad de los requerimientos mínimos sugeridos relativos a disponibilidad de mecanismos de consultas, valoración de servicios, actas de entes de participación y normas que las regulan, entre otros requerimientos. Los municipios con mejores puntajes fueron: Ciudad Autónoma de Buenos Aires, Mar del Plata y La Plata, todas con 6 puntos sobre 7. Un $50 \%$ de los municipios obtuvo una calificación positiva en menos del $25 \%$ de los indicadores de esta categoría.

\section{Gráfico 18: Porcentaje de municipios según nivel de cumplimiento del Eje Participación Ciudadana}

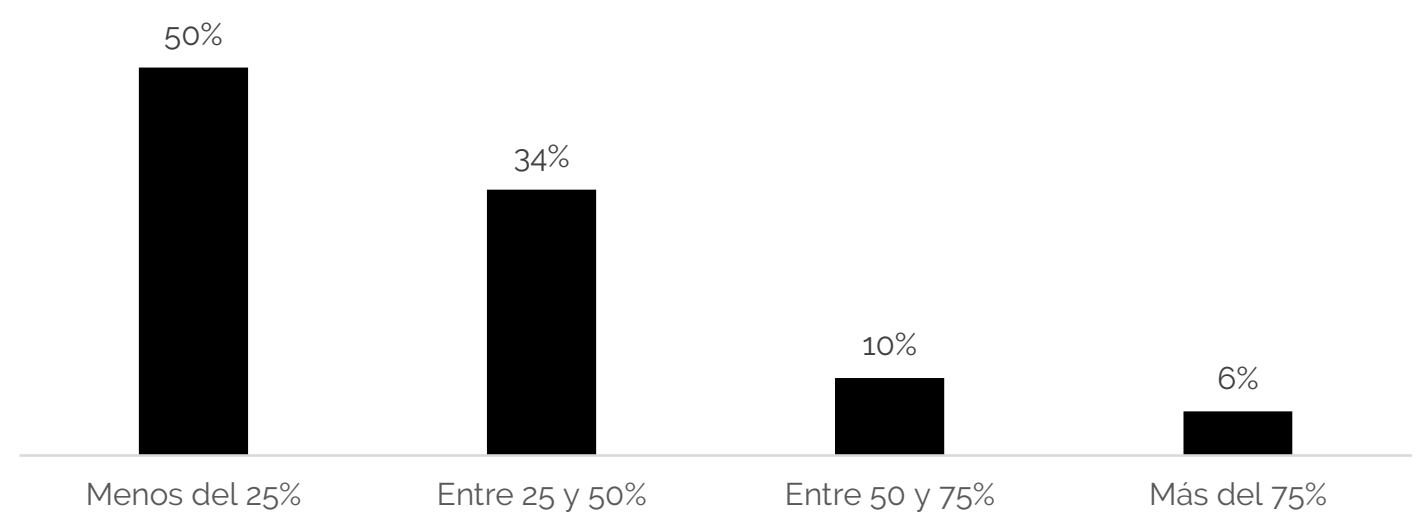

Fuente: Elaboración propia

Si se efectúa una revisión geográfica del indicador relevado, tomando en cuenta el promedio del índice alcanzado en las tres localidades más pobladas de cada provincia (a excepción de CABA, que se analiza de manera individual), se vislumbran marcadas diferencias según cuál sea la provincia que se tome en consideración. Se presenta una mejor situación en la materia en las provincias del centro del país, siendo las provincias del norte y Patagonia las más relegadas.

En el estudio por categoría de análisis, se mantiene una tendencia observada en 2019, en donde los ejes vinculados al presupuesto, y a las contrataciones y licitaciones, son los menos transparentes, con puntajes medios - bajos en más de la mitad del territorio nacional. Por otro lado, los indicadores vinculados con las autoridades presentaron un buen desempeño, aun cuando en la mayoría de los casos hubo modificaciones en los equipos de funcionarios públicos, y se mantienen con un puntaje intermedio los aspectos de participación ciudadana, que tomaron especial interés tras la emergencia sanitaria, y las disposiciones de aislamiento y distanciamiento social.

Aquí merece la pena aclarar, que el promedio puede no ser el más representativo de la situación local. Así, por ejemplo, en el caso de Lanús, cuyo puntaje es significativamente menor al de La Plata y Mar del Plata, sesga a la baja el promedio 
de la Provincia de Buenos Aires. Es por esto, que se presentan a continuación los indicadores desagregados por jurisdicción.

\section{Mapa 2: Diagnóstico provincial promedio. Índice general. Año 2020}

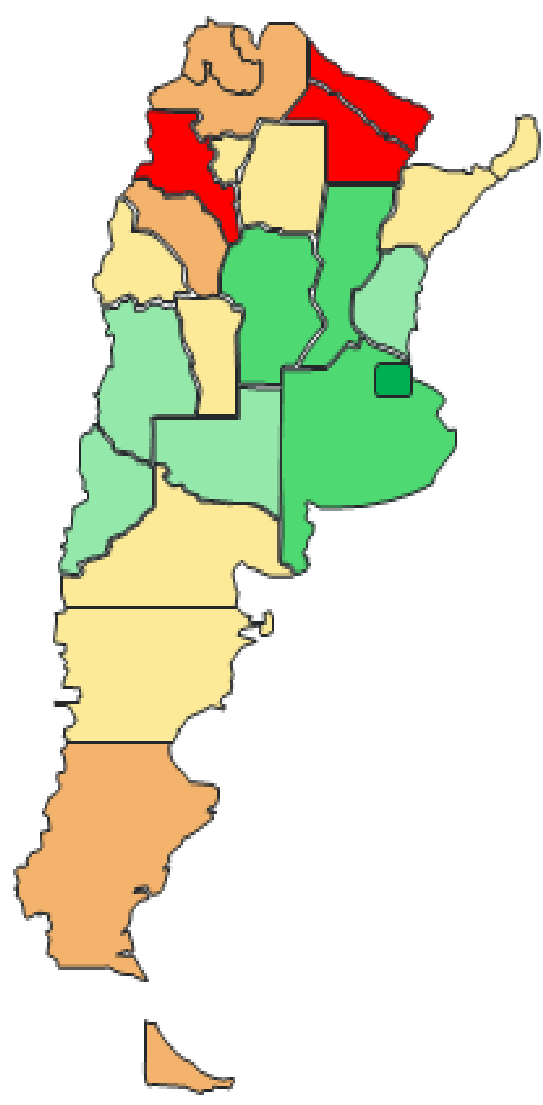

$$
\begin{gathered}
0-20 \\
20-40 \\
40-60 \\
60-80 \\
80-100
\end{gathered}
$$

Fuente: Elaboración propia

Resulta relevante resaltar, que - si bien a priori - se podría suponer que aquellas jurisdicciones con mayores ingresos fiscales per cápita podrian tener mejores indices de transparencia, esa situación no se verifica a simple vista en el mapa provincial. En efecto, las provincias de Tierra del Fuego, Santa Cruz, La Pampa y Catamarca, se encuentran entre aquellas con mayores ingresos totales per cápita, según se desprende de la Dirección Nacional de Asuntos Provinciales, y su nivel de transparencia es menor al deseable. La Ciudad Autónoma de Buenos Aires, seguida por las provincias de Santa Fe, Córdoba y Buenos Aires, se posicionan por encima del promedio nacional (ubicado en 64 puntos) en el índice. En el extremo opuesto se encuentra la provincia de Formosa, cuya calificación fue la más desfavorable, en más del $50 \%$ de los indicadores relevados. 
Tabla 10: Diagnóstico provincial, por categoría. Peor valuación = 100. Año 2020

\begin{tabular}{|c|c|c|c|c|c|c|c|c|c|}
\hline Provincias & Autoridades & $\begin{array}{c}\text { Órganos } \\
\text { de } \\
\text { gobierno }\end{array}$ & $\begin{array}{c}\text { Rendición } \\
\text { de } \\
\text { Cuentas }\end{array}$ & Presupuesto & $\begin{array}{l}\text { Contrataciones } \\
\text { y licitaciones }\end{array}$ & $\begin{array}{l}\text { Comunicacion } \\
\text { institucional }\end{array}$ & $\begin{array}{c}\text { Información } \\
\text { general }\end{array}$ & $\begin{array}{l}\text { Participación } \\
\text { ciudadana }\end{array}$ & TOTAL \\
\hline Buenos Aires & 70 & 35 & 63 & 58 & 14 & 72 & 59 & 23 & 44 \\
\hline CABA & 50 & 0 & 0 & 0 & 0 & 0 & 0 & 0 & 0 \\
\hline Catamarca & 86 & 85 & 89 & 94 & 76 & 80 & 86 & 100 & 83 \\
\hline Chaco & 66 & 95 & 79 & 100 & 100 & 92 & 100 & 83 & 82 \\
\hline Chubut & 66 & 85 & 58 & 88 & 52 & 52 & 91 & 80 & 66 \\
\hline Córdoba & 91 & 15 & 37 & 73 & 43 & 64 & 59 & 34 & 39 \\
\hline Corrientes & 77 & 65 & 74 & 100 & 76 & 64 & 45 & 63 & 65 \\
\hline Entre Ríos & 57 & 65 & 32 & 52 & 48 & 52 & 55 & 57 & 51 \\
\hline Formosa & 57 & 100 & 100 & 100 & 100 & 100 & 73 & 89 & 89 \\
\hline Jujuy & 68 & 85 & 95 & 88 & 67 & 76 & 100 & 83 & 78 \\
\hline La Pampa & 66 & 15 & 63 & 91 & 57 & 60 & 64 & 71 & 60 \\
\hline La Rioja & 30 & 75 & 100 & 94 & 100 & 76 & 91 & 66 & 78 \\
\hline Mendoza & 61 & 80 & 42 & 39 & 48 & 76 & 73 & 80 & 56 \\
\hline Misiones & 100 & 80 & 47 & 76 & 52 & 68 & 64 & 80 & 62 \\
\hline Neuquén & 57 & 70 & 79 & 88 & 76 & 68 & 64 & 74 & 71 \\
\hline Rio Negro & 18 & 35 & 47 & 58 & 43 & 68 & 59 & 63 & 53 \\
\hline Salta & 68 & 70 & 95 & 100 & 100 & 76 & 59 & 83 & 76 \\
\hline San Juan & 77 & 65 & 74 & 64 & 90 & 72 & 86 & 77 & 68 \\
\hline San Luis & 82 & 60 & 74 & 94 & 81 & 68 & 86 & 74 & 71 \\
\hline Santa Cruz & 70 & 55 & 84 & 94 & 90 & 76 & 95 & 97 & 77 \\
\hline Santa Fe & 0 & 30 & 53 & 58 & 14 & 60 & 27 & 40 & 37 \\
\hline Santiago del Estero & 61 & 95 & 84 & 94 & 100 & 80 & 82 & 51 & 74 \\
\hline Tierra del Fuego & 64 & 65 & 74 & 88 & 81 & 76 & 86 & 83 & 76 \\
\hline Tucumán & 48 & 60 & 74 & 100 & 81 & 84 & 64 & 77 & 70 \\
\hline
\end{tabular}

Fuente: Elaboración propia

A nivel municipal, CABA se ubica en primer lugar, y luego le siguen la ciudad de Córdoba, Mar del Plata y Rosario, en ese orden, con un desempeño medio-alto. Entre los municipios con altos niveles de transparencia también se encuentran Godoy Cruz (Mendoza), La Plata (Buenos Aires), Ciudad de Santa Fe, Paraná (Entre Ríos) y la ciudad de Neuquén. 
Tabla 11: Ranking de municipios de acuerdo al nivel de transparencia obtenido. Peor valuación = 100. Año 2020

\begin{tabular}{|c|c|c|c|}
\hline Posición & Municipio & Provincia & Índice \\
\hline 1 & CABA & CABA & 0,0 \\
\hline 2 & Ciudad de Córdoba & Córdoba & 10,3 \\
\hline 3 & Mar del Plata & Buenos Aires & 17.9 \\
\hline 4 & Rosario & Santa Fe & 20,5 \\
\hline 5 & Godoy Cruz & Mendoza & 38,5 \\
\hline 6 & La Plata & Buenos Aires & 39.7 \\
\hline 7 & Ciudad de Santa Fe & Santa Fe & 41,0 \\
\hline 8 & Paraná & Entre Ríos & 41,0 \\
\hline 9 & Ciudad de Neuquén & Neuquén & 42,3 \\
\hline 10 & Río Cuarto & Córdoba & 42,3 \\
\hline 11 & Concordia & Entre Ríos & 43,6 \\
\hline 12 & Corrientes & Corrientes & 43,6 \\
\hline 13 & Santa Rosa & La Pampa & 46,2 \\
\hline 14 & San Carlos de Bariloche & Rio Negro & 47.4 \\
\hline 15 & Viedma & Rio Negro & 47,4 \\
\hline 16 & Comodoro Rivadavia & Chubut & 48,7 \\
\hline 17 & Rafaela & Santa Fe & 48,7 \\
\hline 18 & San Salvador de Jujuy & Jujuy & 53,8 \\
\hline 19 & Posadas & Misiones & 56,4 \\
\hline 20 & Ciudad de Salta & Salta & 57.7 \\
\hline 21 & Ciudad de San Juan & San Juan & 57.7 \\
\hline 22 & Guaymallén & Mendoza & 57.7 \\
\hline 23 & Oberá & Misiones & 59,0 \\
\hline 24 & San Miguel de Tucumán & Tucumán & 59,0 \\
\hline 25 & Villa María & Córdoba & 59,0 \\
\hline 26 & $\begin{array}{l}\text { San Fernando del Valle de } \\
\text { Catamarca }\end{array}$ & Catamarca & 60,3 \\
\hline 27 & General Pico & La Pampa & 61,5 \\
\hline 28 & Goya & Corrientes & 61,5 \\
\hline 29 & Rawson & San Juan & 61,5 \\
\hline 30 & Villa Mercedes & San Luis & 61,5 \\
\hline 31 & Ciudad de La Rioja & La Rioja & 62,8 \\
\hline 32 & Ciudad de San Luis & San Luis & 62,8 \\
\hline 33 & General Roca & Rio Negro & 62,8 \\
\hline 34 & Ciudad de Santiago del Estero & $\begin{array}{l}\text { Santiago del } \\
\text { Estero }\end{array}$ & 66.7 \\
\hline 35 & Puerto Madryn & Chubut & 66.7 \\
\hline
\end{tabular}


Tabla 12: Ranking de municipios de acuerdo al nivel de transparencia obtenido.

Peor valuación = 100. Año 2020 (Continuación)

\begin{tabular}{|c|c|c|c|}
\hline Posición & Municipio & Provincia & Índice \\
\hline 36 & Gualeguaychú & Entre Ríos & 69,2 \\
\hline 37 & Río Gallegos & Santa Cruz & 69,2 \\
\hline 38 & Río Grande & Tierra del Fuego & 69,2 \\
\hline 39 & Eldorado & Misiones & 70,5 \\
\hline 40 & Resistencia & Chaco & 70,5 \\
\hline 41 & Ushuaia & Tierra del Fuego & 70,5 \\
\hline 42 & General Acha & La Pampa & 71,8 \\
\hline 43 & Las Heras & Mendoza & 71,8 \\
\hline 44 & Lanús & Buenos Aires & 73.1 \\
\hline 45 & Yerba Buena & Tucumán & 73,1 \\
\hline 46 & Termas de Río Hondo & Santiago del Estero & 75,6 \\
\hline 47 & Banda del Río Salí & Tucumán & 76,9 \\
\hline 48 & Chilecito & La Rioja & 76.9 \\
\hline 49 & La Banda & Santiago del Estero & 78,2 \\
\hline 50 & Pico Truncado & Santa Cruz & 78,2 \\
\hline 51 & San Pedro de Jujuy & Jujuy & 79.5 \\
\hline 52 & Ciudad de Formosa & Formosa & 80,8 \\
\hline 53 & Tartagal & Salta & 82,1 \\
\hline 54 & Trelew & Chubut & 82,1 \\
\hline 55 & Caleta Olivia & Santa Cruz & 84,6 \\
\hline 56 & Cutral-co & Neuquén & 84,6 \\
\hline 57 & Rivadavia & San Juan & 84,6 \\
\hline 58 & Centenario & Neuquén & 87,2 \\
\hline 59 & Presidencia Roque Saez Peña & Chaco & 87,2 \\
\hline 60 & San Ramón de la Nueva Orán & Salta & 87,2 \\
\hline 61 & Paso de los Libres & Corrientes & 88,5 \\
\hline 62 & Tolhuin & Tierra del Fuego & 88,5 \\
\hline 63 & Barranqueras & Chaco & 89,7 \\
\hline 64 & Clorinda & Formosa & 89.7 \\
\hline 65 & Merlo & San Luis & 89,7 \\
\hline 66 & Arauco & La Rioja & 93,6 \\
\hline 67 & Santa María & Catamarca & 93,6 \\
\hline 68 & Valle Viejo & Catamarca & 96,2 \\
\hline 69 & Pirané & Formosa & 97,4 \\
\hline 70 & Palpalá & Jujuy & 100,0 \\
\hline
\end{tabular}

Fuente: Elaboración propia 


\subsection{Diagnóstico comparado 2019-2020}

Del análisis comparado, surge que sólo 16 municipios mejoraron su performance para el 2020 respecto del año anterior (23\% del total) Mientras que el 73\% de los municipios relevados empeoraron su desempeño respecto al 2019, y el $4 \%$ restante mantuvo su posición relativa. Esto deja en evidencia que el cambio de autoridades sumado a la emergencia sanitaria en muchos casos obligó a redireccionar esfuerzos hacia otros ejes de la política pública (como la educación o la salud pública), relegando aspectos de modernización y gobierno abierto, a un plano secundario.

\section{Gráfico 19: Porcentaje de municipios según su evolución de transparencia 2020 vs. 2019}

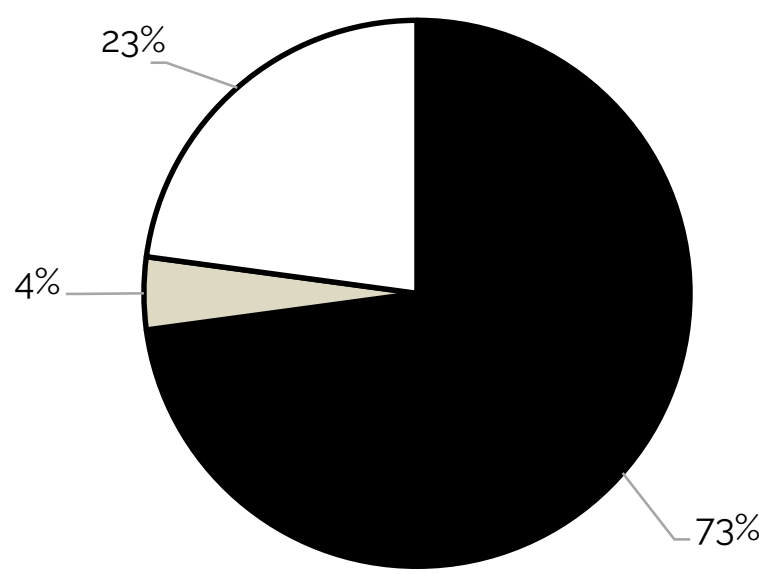

- Peor algual aMejor

\section{Fuente: Elaboración propia}

A nivel general, se observa que donde hubo mejoras fue en el relacionado a Órganos de gobierno donde alrededor del 47\% de los municipios aumentaron su puntuación en este eje respecto a 2019. Mientras que en Presupuesto, Contrataciones y licitaciones no se observaron modificaciones. En sentido opuesto, se observó una caída en el desempeño respecto al año anterior en el Eje de Información General (90\% de los municipios obtuvo una caída), Participación Ciudadana (66\%), Autoridades (53\%), Rendición de Cuentas (47\%) y Comunicación Institucional (41\%). Vale mencionar que los ejes en los que se identificó un retroceso en el desempeño con respecto al año 2019 son aquellos más afectados por la irrupción de la pandemia en el desarrollo normal de las actividades como, por ejemplo, información sobre actividades municipales y ciudadanas, mecanismos de participación, rendición de cuenta sobre planes y programas de gobierno, entre otros. 
Gráfico 20: Porcentaje de municipios según su evolución 2020-2018 por eje de análisis

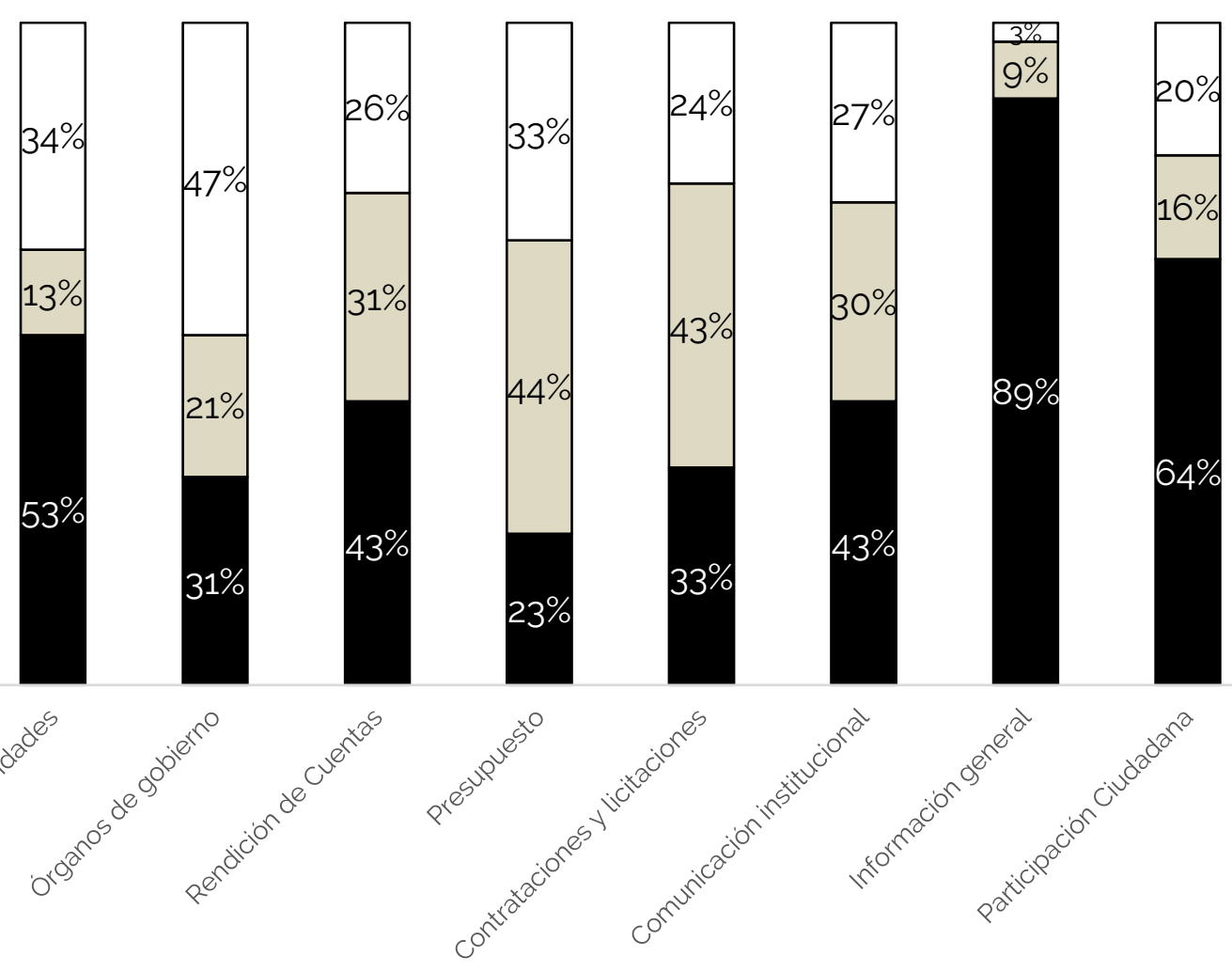

- Peor algual aMejor

Fuente: Elaboración propia 
Si se analiza en detalle cada categoria, se observa que en el eje de Autoridades las caídas fueron entre los niveles más altos de cumplimiento donde $6 \%$ de los municipios que antes alcanzaban valores de cumplimiento por encima del $50 \%$ ahora se concentran en niveles entre el 25 y 50\% de cumplimiento.

\section{Gráfico 21: Nivel de cumplimiento en el Eje Autoridades comparando 2019 y 2020}

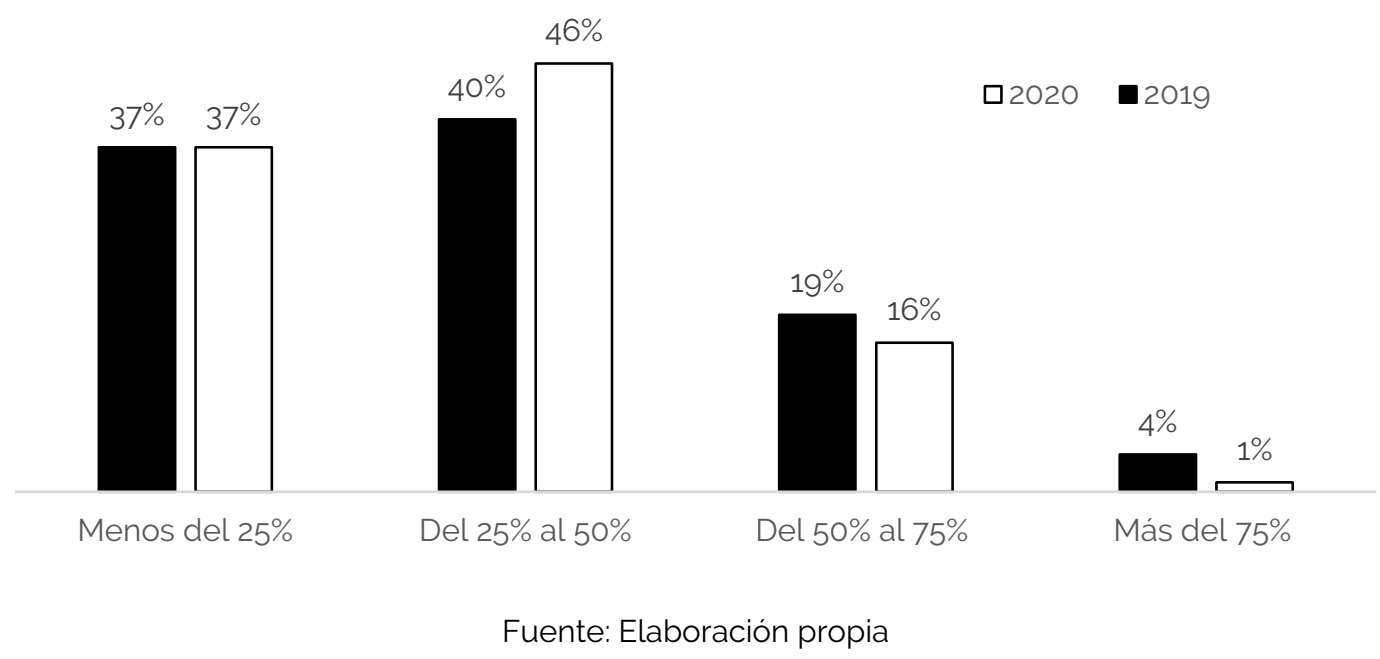

Como se mencionó, uno de los ejes en donde hubo mejoras fue en el de Órganos de gobierno, incrementándose el porcentaje de municipios que alcanzan un nivel de cumplimiento de más del 50\%.

\section{Gráfico 22: Nivel de cumplimiento en el Eje Órganos de gobierno comparando 2019 y 2020}

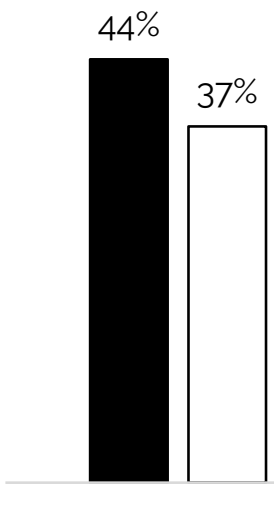

Menos del 25\%

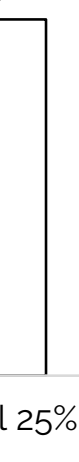

$\square 2020$

2019

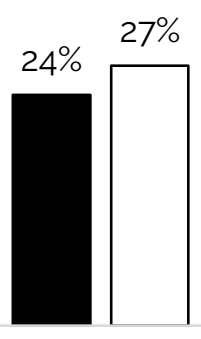

Del $50 \%$ al $75 \%$

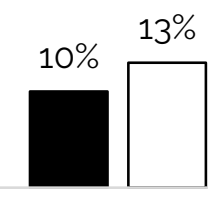

Más del $75 \%$

Fuente: Elaboración propia 
En el caso de la Rendición de Cuentas donde se identifica una caída en el desempeño de los municipios, el gráfico muestra que la caída más evidente es entre los municipios con alto nivel de cumplimiento (más del 75\%) que pasa del 33\% del total al $13 \%$.

\section{Gráfico 23: Nivel de cumplimiento en el Eje Rendición de Cuentas comparando 2019 y 2020}

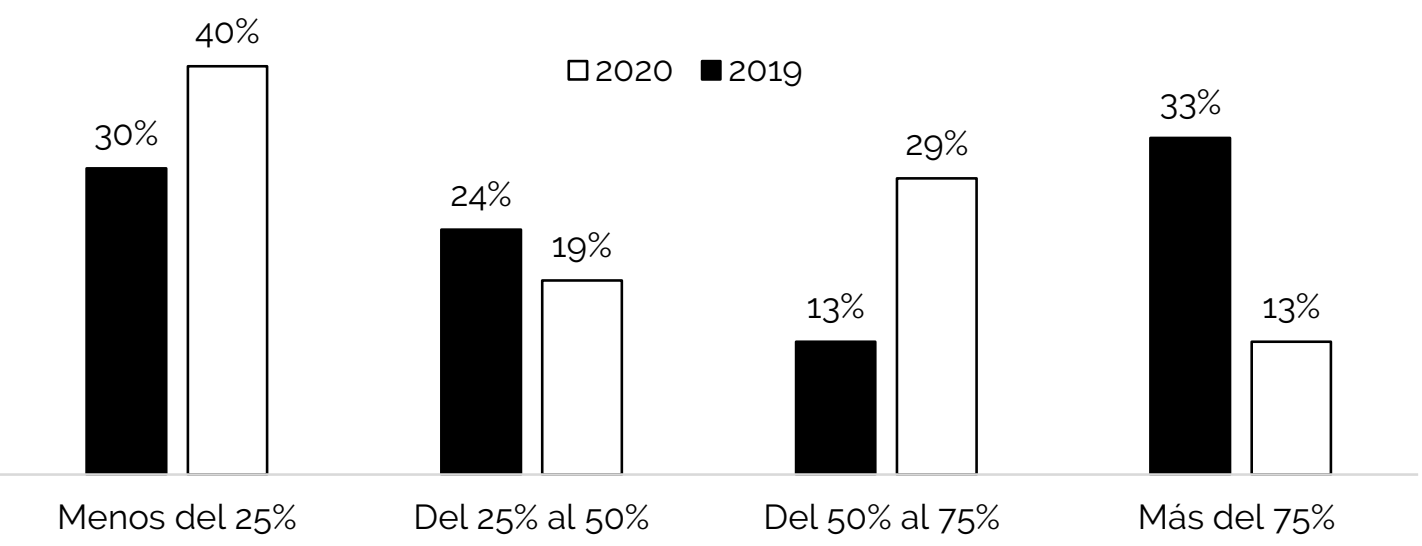

Fuente: Elaboración propia

Para el eje de Presupuesto, la distribución de los municipios según nivel de cumplimiento se mantiene relativamente similar entre años con un incremento en el porcentaje de municipios que alcanzaron un cumplimiento del $75 \%$ de los requerimientos de los indicadores de este eje.

\section{Gráfico 24: Nivel de cumplimiento en el Eje Presupuesto comparando 2019 y 2020}

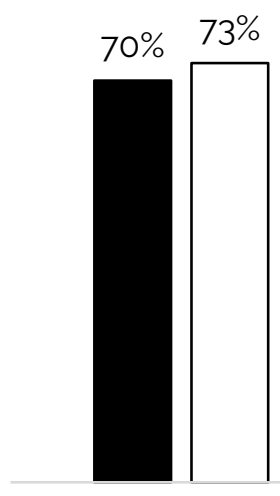

Menos del 25\%
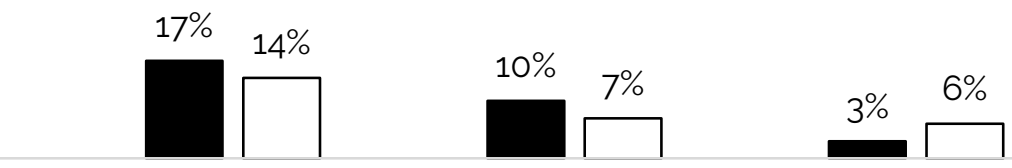

Del $25 \%$ al $50 \%$

Del $50 \%$ al $75 \%$

Más del $75 \%$

Fuente: Elaboración propia 
Similar situación se observa en el caso del Eje de Compras y contrataciones públicas con la diferencia de que en 2020 ningún municipio alcanza cumplir con el 50\% de los indicadores correspondientes a este eje mientras que en 2019 al menos un 4\% de los municipios lo alcanzaba.

\section{Gráfico 25: Nivel de cumplimiento en el Eje Compras y contrataciones comparando 2019 y 2020}

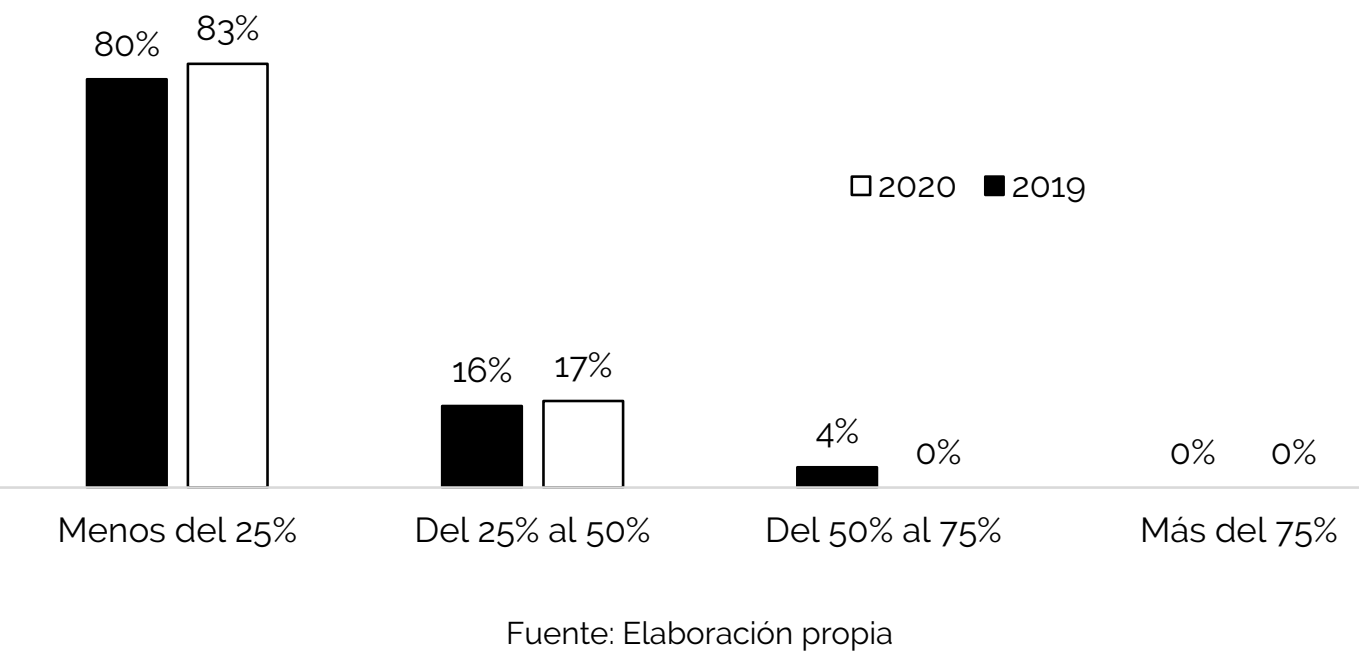

En lo que refiere a Comunicación institucional, en la comparativa entre años, también existe una caída en el desempeño de los municipios, observándose una baja importante en el porcentaje de aquellos que alcanzaban entre un 50 y $75 \%$ de cumplimiento de los indicadores e incremento entre los municipios que alcanzar un nivel por debajo del 50\%.

\section{Gráfico 26: Nivel de cumplimiento en el Eje Comunicación institucional comparando 2019 y 2020}

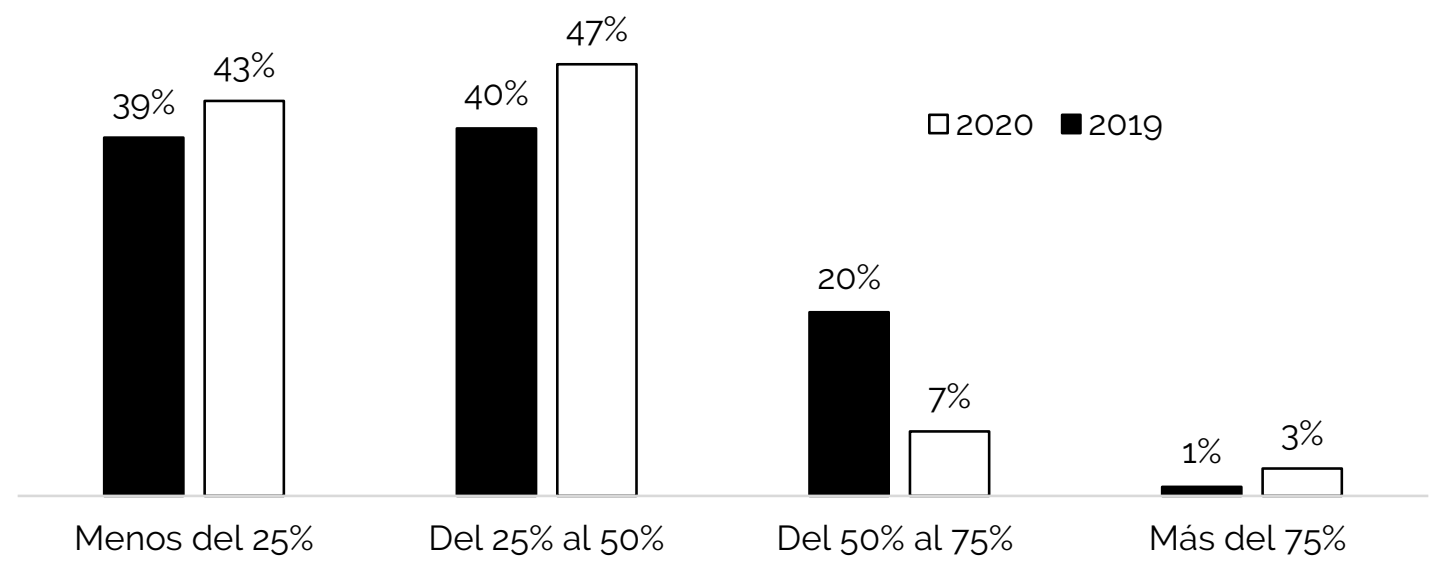

Fuente: Elaboración propia 
En la comparación entre años, destaca el cambio entorno al nivel de cumplimiento en el Eje Información General donde existe una fuerte caída en el desempeño. El porcentaje de municipios que alcanza un nivel de cumplimiento de más del $75 \%$ de los indicadores cae del $76 \%$ al $14 \%$.

\section{Gráfico 27: Nivel de cumplimiento en el Eje Información General comparando 2019 y 2020}

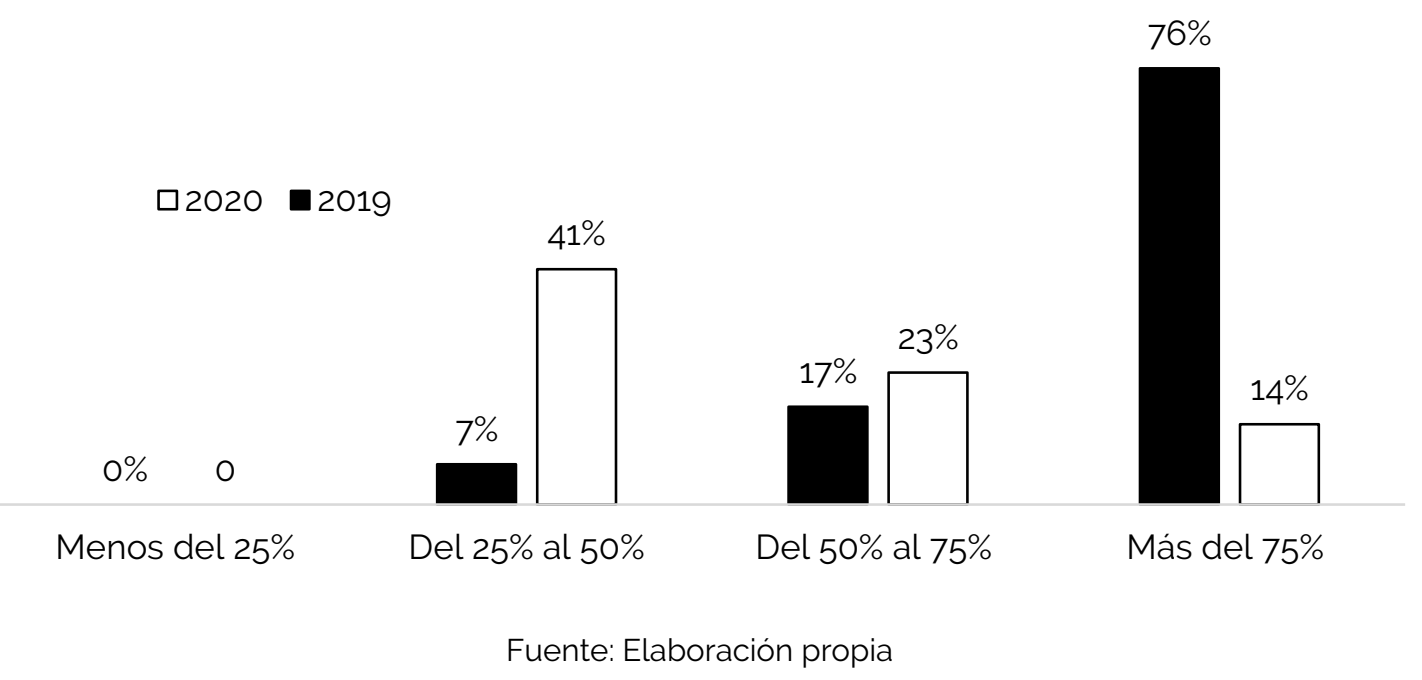

Por último, en el caso del eje Participación Ciudadana donde el 66\% de los municipios empeoró su desempeño, la mayoría de los municipios pasó a ubicarse en un bajo nivel de cumplimiento de los indicadores, por debajo del $25 \%$.

\section{Gráfico 28: Nivel de cumplimiento en el Eje Participación Ciudadana comparando 2019 y 2020}

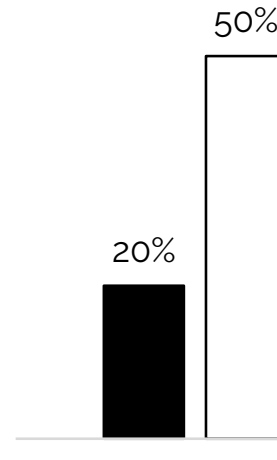

Menos del 25\%

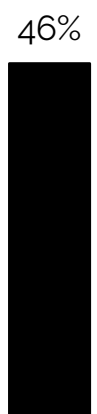

Del 25\% al 50\%

$34 \%$

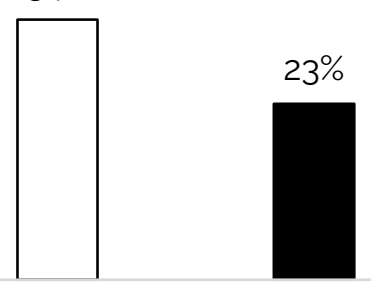

Del 50\% al 75\%

$10 \%$
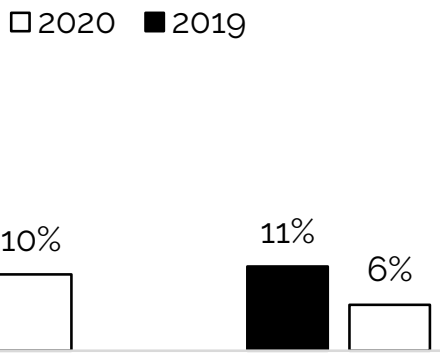

Más del 75\%

Fuente: Elaboración propia 
A nivel provincial, sólo tres provincias presentaron mejoras en su desempeño respecto a 2019: Río Negro, Santiago del Estero y Tucumán, a las que se suma la Ciudad Autónoma de Buenos Aires; mientras que el resto empeoró respecto al año anterior.

Si se analiza de manera comparada el desagregado por municipio lo acontecido entre el año 2019 y 2020, se pueden sacar algunos comentarios de interés. En primer lugar, se debe considerar que la mayoría de los municipios presentó un retroceso a nivel interanual. Sin embargo, se debe destacar el caso de Ciudad Autónoma de Buenos Aires, que ha mejorado su puntuación respecto del año anterior, en la mitad de los ejes bajo análisis. En segundo lugar, aparece el caso de las municipalidades de Santiago del Estero, que si bien han tenido una puntuación media en el corriente año mejoraron su performance respecto de lo registrado en 2019. Finalmente, las restantes localidades con mejoras corresponden, mayoritariamente, a ciudades cabeceras salvo pequeñas excepciones.

\subsection{Relación con estudios en Ecuador y España}

Un análisis adicional surge de comparar los resultados obtenidos en Argentina con las experiencias de España y Ecuador6. En primer lugar, se observa una predominancia de gobiernos locales de mediana/baja escala (con poblaciones menores a 125.000 habitantes) en la muestra tomada en consideración. Por otro lado, los resultados son menos alentadores para los países latinoamericanos. En Argentina, solamente $6 \%$ de los municipios relevados logró un puntaje superior al 50\%, mientras que en Ecuador (de los 105 municipios tomados en consideración) tan solo un 1\% logró ese puntaje; por lo contrario, en España, el 49,3\% de los municipios (109 de 221) se ubican en la posición máxima. Por otra parte, Argentina presenta el mayor porcentaje de municipios (54\%) con un puntaje menor al $25 \%$, mientras que en Ecuador es del $46 \%$ y en España el $8 \%$.

Por otro lado, mientras en España las alcaldias más pobladas muestran mejores resultados en materia de transparencia, en Ecuador y Argentina, dichos resultados son medios/bajos, según sea el caso.

\footnotetext{
6 mapainfoparticipa.com Para el caso de España, se toman los informes 2017 que incluyen 221 alcaldias ubicadas en: Andalucia, Canarias, Catalunya, Galicia, País Vasco y Madrid.
} 
Tabla 13: Distribución de municipios relevados de acuerdo según cantidad de habitantes. Casos Argentina, España y Ecuador

\begin{tabular}{|c|c|c|c|}
\hline \multirow{2}{*}{$N^{\circ}$ DE HABITANTES } & \multicolumn{3}{|c|}{ CANTIDAD DE MUNICIPIOS } \\
\cline { 2 - 4 } Más de 500.000 & Argentina & Ecuador & España \\
\hline De 250.001 a 500.000 & 9 & 3 & 3 \\
\hline De 125.001 a 250.000 & 12 & 3 & 4 \\
\hline De 62.501 a 125.000 & 20 & 13 & 23 \\
\hline De 31.001 a 62.500 & 13 & 43 & 46 \\
\hline Hasta 31.000 & 7 & 19 & 96 \\
\hline Total & 70 & 105 & 221 \\
\hline
\end{tabular}

Tabla 14: Porcentaje de municipios relevados según cantidad de habitantes que alcanzaron más del $\mathbf{5 0 \%}$ de indicadores positivos. Casos Argentina, Ecuador y

España

\begin{tabular}{|c|c|c|c|c|c|c|}
\hline \multirow{2}{*}{$\begin{array}{c}N^{\circ} \text { DE } \\
\text { HABITANTES }\end{array}$} & \multicolumn{5}{|c|}{ WEBS CON MÁS DEL 50\% DE INDICADORES POSITIVOS } \\
\cline { 2 - 7 } & $\begin{array}{c}\text { Argentin } \\
\mathrm{a}\end{array}$ & $\%$ Total & Ecuador & $\%$ Total & España & $\%$ Total \\
\hline Más de 500.000 & 3 & $33 \%$ & 1 & $33 \%$ & 3 & $100 \%$ \\
\hline $\begin{array}{c}\text { De } 250.001 \mathrm{a} \\
500.000\end{array}$ & 0 & $0 \%$ & 0 & $0 \%$ & 4 & $100 \%$ \\
\hline $\begin{array}{c}\text { De } 125.001 \mathrm{a} \\
250.000\end{array}$ & 2 & $17 \%$ & 0 & $0 \%$ & 20 & $87 \%$ \\
\hline $\begin{array}{c}\text { De } 62.501 \mathrm{a} \\
125.000\end{array}$ & 1 & $5 \%$ & 0 & $0 \%$ & 26 & $57 \%$ \\
\hline $\begin{array}{c}\text { De 31.001 a } \\
62.500\end{array}$ & 0 & $0 \%$ & 0 & $0 \%$ & 22 & $45 \%$ \\
\hline Hasta 31.000 & 0 & $0 \%$ & 0 & $0 \%$ & 34 & $35 \%$ \\
\hline Total & 6 & $6 \%$ & 1 & $1 \%$ & 109 & $49 \%$ \\
\hline
\end{tabular}


Tabla 15: Porcentaje de municipios relevados según cantidad de habitantes que alcanzaron entre el $\mathbf{2 5} \%$ y el $\mathbf{5 0} \%$ de indicadores positivos. Casos Argentina, Ecuador y España

\begin{tabular}{|c|c|c|c|c|c|c|}
\hline \multirow{2}{*}{$\begin{array}{c}\text { N DE } \\
\text { HABITANTES }\end{array}$} & \multicolumn{6}{|c|}{ WEBS ENTRE EL 25\% Y 50\% DE INDICADORES POSITIVOS } \\
\cline { 2 - 7 } & Argentina & $\%$ Total & Ecuador & $\%$ Total & España & $\%$ Total \\
\hline $\begin{array}{c}\text { Más de } \\
500.000\end{array}$ & 4 & $44 \%$ & 2 & $67 \%$ & 0 & $0 \%$ \\
\hline $\begin{array}{c}\text { De } 250.001 \text { a } \\
500.000\end{array}$ & 5 & $56 \%$ & 3 & $100 \%$ & 0 & $0 \%$ \\
\hline $\begin{array}{c}\text { De } 125.001 \text { a } \\
250.000\end{array}$ & 3 & $25 \%$ & 10 & $77 \%$ & 3 & $13 \%$ \\
\hline $\begin{array}{c}\text { De 62.501 a } \\
125.000\end{array}$ & 10 & $50 \%$ & 12 & $50 \%$ & 19 & $41 \%$ \\
\hline $\begin{array}{c}\text { De 31.001 a } \\
62.500\end{array}$ & 4 & $31 \%$ & 24 & $56 \%$ & 21 & $43 \%$ \\
\hline Hasta 31.000 & 0 & $0 \%$ & 5 & $26 \%$ & 51 & $53 \%$ \\
\hline Total & 26 & $37 \%$ & 56 & $53 \%$ & 94 & $43 \%$ \\
\hline
\end{tabular}

Tabla 16: Porcentaje de municipios relevados según cantidad de habitantes que alcanzaron menos del 25\% de indicadores positivos. Casos Argentina, Ecuador y España

\begin{tabular}{|c|c|c|c|c|c|c|}
\hline \multirow{2}{*}{$\begin{array}{c}N^{\circ} \text { DE } \\
\text { HABITANTES }\end{array}$} & \multicolumn{5}{|c|}{ WEBS CON MENOS DEL 25\% DE INDICADORES POSITIVOS } \\
\cline { 2 - 7 } & Argentina & $\%$ Total & Ecuador & $\%$ Total & España & $\%$ Total \\
\hline $\begin{array}{c}\text { Más de } \\
500.000\end{array}$ & 2 & $22 \%$ & 0 & $0 \%$ & 0 & $0 \%$ \\
\hline $\begin{array}{c}\text { De } 250.001 \mathrm{a} \\
500.000\end{array}$ & 4 & $44 \%$ & 0 & $0 \%$ & 0 & $0 \%$ \\
\hline $\begin{array}{c}\text { De } 125.001 \mathrm{a} \\
250.000\end{array}$ & 7 & $58 \%$ & 3 & $23 \%$ & 0 & $0 \%$ \\
\hline $\begin{array}{c}\text { De } 62.501 \mathrm{a} \\
125.000\end{array}$ & 9 & $45 \%$ & 12 & $50 \%$ & 1 & $2 \%$ \\
\hline $\begin{array}{c}\text { De 31.001 a } \\
62.500\end{array}$ & 9 & $69 \%$ & 19 & $44 \%$ & 6 & $12 \%$ \\
\hline Hasta 31.000 & 7 & $100 \%$ & 14 & $74 \%$ & 11 & $11 \%$ \\
\hline Total & 38 & $54 \%$ & 48 & $46 \%$ & 18 & $8 \%$ \\
\hline
\end{tabular}




\section{Comentarios finales}

Los resultados obtenidos del estudio comparado permiten varios análisis en torno al desempeño de los municipios con respecto a la transparencia. Por un lado, permite observar el grado de avance con la finalidad de ver las fortalezas y obstáculos que enfrentan. De esta manera, se busca identificar en qué aspectos se deben realizar mayores esfuerzos tanto a nivel de cada municipio como del conjunto. Por otro, considerar el impacto del COVID-19 como elemento adicional de análisis al evaluar el desempeño de los gobiernos locales (especialmente en relación a la gestión pública) durante 2020 .

En cuanto al desempeño de los municipios, la comparativa interanual, muestra una caída a nivel general. En 2020 el promedio general fue de 13,5 frente al 17,3 puntos de 2019. El bajo desempeño, tanto del corriente año, como el de 2019, se explican en parte, por el incipiente estado en la materia por parte de Argentina, que se vislumbra en las estadísticas internacionales, especialmente a nivel subnacional. Adicionalmente, debe considerarse el impacto que posiblemente tuvo la crisis del COVID-19 en la evolución. El dato de que sólo 23\% de los municipios logró alguna mejora en su desempeño respecto al año anterior, delata un retroceso en vez de un avance en la materia. Si bien se podría argumentar que el contexto pudo incidir en este desarrollo, al mismo tiempo, se observan municipios que mejoraron su desempeño respecto del año anterior. La identificación de estos casos puede justificar un ulterior análisis más profundo sobre las estrategias y acciones llevadas a cabo por éstos para lograr este éxito aún en medio de un contexto desfavorable. especialmente cuando en muchas ocasiones el impulso generado por la pandemia no se materializó en una gestión pública local más eficiente e integral. A nivel nacional, se recomienda aprovechar los análisis detallados realizados para cada una de las webs, como así también las iniciativas que surgieron en el marco de la emergencia sanitaria, a modo de poder realizar un diagnóstico integral en la materia.

A nivel provincial, surge que el mejor desempeño corresponde a las localidades ubicadas en el centro, quedando relegadas aquellas provincias del norte y sur del país. Por otro lado, al igual que en otros estudios similares, al interior de cada provincia se destacan - en casi todos los casos - las localidades cabeceras, por sobre las demás jurisdicciones tomadas en consideración.

Como aspecto negativo, aparece que - si bien se observan leves mejoras en algunos de los ámbitos en cuestión - la irrupción de la emergencia sanitaria, parece haber relegado esfuerzos hacia otros ámbitos de la política pública lo que va en dirección opuesta a las recomendaciones. Esto amerita especial atención pues la pandemia implicó una crisis donde la información sobre las decisiones de gobierno asume vital importancia para generar confianza en medio de un contexto de incertidumbre donde por otra parte los canales de comunicación se vieron reducidos, tomando especial protagonismo los canales online. 
Al igual que en otros estudios, se observan deficiencias en lo referente a herramienta de participación. Aparecen pocos ejemplos de participación ciudadana, colaboración directa proveniente de la sociedad civil como: laboratorios de ideas, presupuestos colaborativos o iniciativas similares. Aun cuando el contexto de virtualidad a causa de la pandemia podría haber servido de plataforma para su creación o aceleración. Como agravante, incluso, se vislumbra que en muchas ocasiones se resintieron o redujeron sustancialmente las actividades de los diferentes poderes del gobierno en lugar de garantizar la continuidad por medios remotos o digitales. En este sentido, no solo resulta relevante contar con canales de interacción ciudadana, sino también que se publiquen sus actas en tiempo y forma, los instructivos de participación y se mantenga la fluidez de estos canales para canalizar adecuadamente las demandas ciudadanas y reducir la necesidad de presencialidad.

Un aspecto a destacar es que, pese al bajo desempeño del total de los municipios, la existencia de casos que mejoraron respecto al año anterior, evidencia la necesidad y relevancia que algunas localidades están asignando al gobierno abierto por lo cual están desarrollando planes o políticas constantes en este sentido. De hecho, como se destacó al comienzo de este documento, muchas de las acciones implementadas durante la pandemia tuvieron relacionadas a mejorar la comunicación con el ciudadano, ofrecer información, informatizar trámites y transparentar procesos y procedimientos de la gestión pública; lo cual - en algunos casos - no llegó a impactar en el indicador por lo pequeño y extraordinario de las mismas, o por corresponder a medidas aisladas que no poseen un correlato en la estrategia de politica local.

Como se manifiesta del análisis, si bien en materia de presupuesto y contrataciones y licitaciones, no se observaron a nivel general retrocesos tampoco hubo avances en esta materia, lo cual resulta un llamado de atención, por ser un área tan importante en pro de una mayor responsabilidad y eficiencia en la gestión pública. Esto se agrava si se considera como argumentan algunos especialistas que en situaciones de emergencia como una pandemia o en etapas de recuperación postcrisis se manifiestan riesgos altos de uso indebido de los recursos públicos (Khasiani et al., 2020). Cuando hay fraude y corrupción se pierde dinero indispensable para enfrentar la crisis de manera efectiva. Esto, a su vez, genera un círculo vicioso donde se ve afectada la gobernabilidad, especialmente por la merma de la confianza de la ciudadanía en las instituciones (Pertuzé Fariña, 2003:24).

En lo que refiere a la digitalización y sistematización de la operatoria gubernamental (modernización de la gestión), salvo casos puntuales (Ciudad Autónoma de Buenos Aires, Córdoba, Rosario, entre otras), no ha habido cambios significativos en el 2020 respecto de lo observado en 2019. Sin embargo, la emergencia sanitaria, y la correspondiente adaptación del sector público a esta situación, dejan entrever su gran potencial. 
Aparecen adicionalmente, municipios que no cuentan con canales oficiales de comunicación para con la ciudadanía, lo cual se sugiere revisar a futuro. Si bien estas localidades utilizan alguna red social para presentar novedades, información básica, o incluso agendas de funcionarios y de actividades, excluyen de su uso a aquellos usuarios que no las utilizan regularmente, o que no disponen de dichas aplicaciones.

De esta manera, resulta crucial fortalecer los vínculos con la ciudadanía, de manera tal que ésta sea un ente de revisión y control del accionar del Estado, permitiendo que las diferentes acciones realizadas trasciendan los periodos electorales. Se vislumbran líneas concretas de cambio en la materia, implementadas tanto por municipios de gran tamaño como por aquellos de tamaño medio o pequeños, que en muchos casos podrían ser escalables.

Por otra parte, se reconoce la necesidad de mejorar el estudio en próximas ediciones incorporando algunas variables no consideradas en este caso y que si han sido observadas en estudios similares como la variable acerca del sexo del intendente y el partido político al que pertenece el mismo.

A modo de cierre, el presente estudio presenta una oportunidad para evaluar el desempeño de los gobiernos locales en materia de transparencia en base a datos y poder asi ajustar y mejorar las políticas implementadas en tal sentido con el propósito de emprender un avance certero y evidenciable. Esto presenta una relevancia vital tanto para los gobiernos y la sociedad civil en la acción conjunta hacia un gobierno más abierto.

\section{Bibliografía}

BERTOT, J.C. y MUNSON, S.A. 2010. "Using ICTs to create a culture of transparency: E-government and social media as openness and anti-corruption tools for societies", Government Information Quarterly, vol. 27, núm.3: 264-271.

CAMACHO ÁVILA, M.C. 2006. El Enfoque Humanista en la Gerencia. Barinas: Universidad Nacional Experimental de Los Llanos Ezequiel Zamora.

CANEL, M.J. 2018. La comunicación de la administración pública. Para gobernar con la sociedad, México: Fondo de Cultura Económica.

CRIADO, J.I. y RAMILO, M. C. 2003. "E-Government in Practice", International Journal of Public Sector Management, vol. 16, núm.3: 191-218.

DE MIGUEL MOLINA, M. 2010. "E-Government in Spain: An Analysis of the Right to Quality E-Government", International Journal of Public Administration, núm.33: 110. 
DURÁN RUIZ, F.J. 2009. "Retos y oportunidades de la administración y el gobierno electrónico: Derecho a las TIC y alfabetización digital", Zona Próxima, núm. 10: 104125

FENOGLIO, N. 2020. "Análisis de la Ley 27.275, de Derecho de Acceso a la Información Pública Argentina", Revista Ágora, vol. 4, núm. 12: 39-52

GIMENÉZ CHORNET, V. 2012. "Acceso de los ciudadanos a los documentos como transparencia de la gestión pública", Profesional De La Información, vol. 21, núm. 5: 504-508.

HERNÁNDEZ BONIVENTO, J., GANDUR, M.P. y NAILES, J. 2014. "Gobierno Municipal Abierto en América Latina. De la proximidad administrativa a la Acción Colaborativa", New York: Organización de los Estados Americanos.

KHASIANI, K. et al. 2020. "Controles de la ejecución presupuestaria para mitigar el riesgo de corrupción en el gasto por la pandemia", Fiscal Affairs, Serie especial sobre la COVID-19: 1-11.

LATHROP, D. y RUMA, L. 2010. Gobierno Abierto, Sebastopol: O’Reilly

MANFREDI SÁNCHEZ, J.L et al. 2016. "Transparencia y rendición de cuentas de los municipios de Castilla-La Mancha", Revista Castellano-Manchega de Ciencias Sociales, núm. 21: 175-189.

MANFREDI SÁNCHEZ, J.L. 2010. "Periodismo y transparencia informativa", Cuadernos de Periodistas, núm. 19: 113-123

MEIJER, A.J., CURTIN D. y HILLEBRANDT, M. 2012. "Open government: connecting vision and voice", International Review of Administrative Sciences, núm.78: 10-29.

MOLINA, E. y VIEYRA, J. C. 2012. "La transparencia como herramienta de política pública", en DASSEN, N. y VIEYRA, J.C. (Eds.) Gobierno abierto y transparencia focalizada. Tendencias y desafios para América Latina y el Caribe. gente Washington D.C.: Banco Interamericano de Desarrollo, 3-39.

MOLINA RODRIGUEZ NAVAS, P. y MEDRANDA MORALES, N.J. 2018. "La transparencia de los municipios de Ecuador en sus sitios web: metodología y resultados". América Latina Hoy, vol. 80: 143-169.

MOON, M. J., LEE, J. y ROH, C.Y. 2014. "The Evolution of Internal IT Applications and E-Government Studies in Public Administration: Research Themes and Methods", Administration \& Society, núm. 46: 3-36.

MORENO-SARDÁ, A., MOLINA RODRIGUEZ-NAVAS, P. y SIMELIO-SOLÁ, N. 2017. "Impacto de la legislación sobre la transparencia en la información publicada por 
las administraciones locales", El profesional de la información, vol.26, núm.3: 370380

MORENO SARDÁ, A et al. 2021. "Evaluación y mejora de la transparencia de las administraciones públicas locales: metodología Infoparticipa", en Caffarel, C. et al. (eds.), Tendencias metodológicas en la investigación académica sobre Comunicación. Salamanca: Comunicación Social Ediciones y Publicaciones, 273286

NASER, A. y RAMíREZ ALUJAS, Á. 2014. Plan de Gobierno Abierto: una hoja de ruta para los gobiernos de la región, Santiago de Chile: CEPAL-Naciones Unidas

OSZLAK, O. y KAUFMAN, E. 2014. Teoría y práctica del gobierno abierto. Lecciones de la experiencia internacional. IDRC-RedGEalc-OEA

PANDO, D. P. 2017. "No todo lo que brilla es oro: límites, inconsistencias y retos del gobierno abierto en América Latina", Revista Estado Abierto, vol. 1, núm. 2:45-69

PERTUZÉ FARIÑA, C. 2003. "Nuevos tiempos para la gestión pública: potenciando la transparencia", Revista Enfoques: Ciencia Politica y Administración Pública, núm. 1: 19-27

RAMÍREZ ALUJAS, A. 2010. "Innovación en la Gestión Pública y Open Government", Revista Buen Gobierno, vol. 1: 96-133

RAMIREZ ALUJAS, A. 2012. "Gobierno abierto es la respuesta: ¿Cuál era la pregunta?", Más poder local, núm.2: 14-22.

RAMÍREZ ALUJAS, Á. y DASSEN, N. 2014. Vientos de Cambio: el avance de las políticas de gobierno abierto en América Latina y el Caribe. Banco Interamericano de Desarrollo.

RIVERO MENÉNDEZ, J.A, MORA AGUDO, L. y FLORES UREBA, S. 2007. “Un estudio de la rendición de cuentas a través del e-gobierno en la administración local española", Empresa global y mercados locales: XXI Congreso anual Aedem, 1-16

ROBLES LÓPEZ, C. y ZAMORA-MEDINA, R. 2020. "Transparencia online como bien intangible del sector público", Trans/nformação, vol. 32:1-14

RODRIGUEZ NAVAS, P. y MEDRANDA, N. 2018. "La transparencia de los municipios de Ecuador en sus sitios web: metodología y resultados" América Latina Hoy, vol. 80: $143-169$ 


\section{ANEXO I \\ Detalle de indicadores considerados - por categoría}

\section{Autoridades}

1. Información básica sobre el intendente. Nombre, foto, partido

2. Información básica sobre el intendente. Biografia, CV

3. Información básica sobre representantes que forman parte del gobierno municipal: Nombre, foto, partido.

4. Información básica sobre representantes que forman parte del gobierno municipal: Biografía, CV.

5. Información sobre representantes que no forman parte del gobierno municipal: Nombre, foto, partido.

6. Información sobre representantes que no forman parte del gobierno municipal: Biografía, CV.

7. Se publican las remuneraciones de los representantes políticos.

8. Se publican declaraciones de actividades y bienes de los electos.

9. Se publica agenda institucional del intendente.

10. Se publican datos de contacto de los miembros del gobierno.

11. Se publican datos de contacto de los miembros de la oposición.

\section{Órganos de Gobierno}

12. Información sobre la composición de los órganos de gobierno.

13. Sobre las competencias y calendario de trabajo de éstos órganos.

14. Nombres completos de personas responsables y sus funciones.

15. Se publican las convocatorias a sesiones del Concejo Deliberante y órdenes del día.

16. Se publican actas de las sesiones del Concejo, o boletines oficiales.

\section{Rendición de cuentas}

17. Se publican informes anuales de rendición de cuentas.

18. Se publica información sobre planes y programas en ejecución (Plan de Gobierno, Plan Estratégico, metas y objetivos de las unidades administrativas).

19. Se da información sobre Plan de Ordenamiento Territorial y otras normas de planificación urbanística y modificaciones.

20. Se publican ordenanzas municipales. 


\section{Presupuesto}

21. Se publica presupuesto vigente.

22. Se publica información sobre la ejecución mensual del presupuesto.

23. Se publican modificaciones presupuestarias.

24. Se publica información sobre sostenibilidad fiscal y endeudamiento vigente.

25. Se publica la liquidación de presupuestos de ejercicios anteriores o la cuenta general.

26. Se publica la relación de puestos de trabajo y las respectivas remuneraciones.

27. No aplica al caso argentino.

\section{Contrataciones y licitaciones públicas}

28. Se publica información de concursos públicos y resultados

29. Se publica inventario general del patrimonio del municipio.

30. Se publican todos los contratos formalizados.

31. Se publican las licitaciones en curso, metodología y criterio de selección.

32. Se publican las actas de los procesos de contratación.

33. Se publican las modificaciones de los contratos formalizados y sus prórrogas, licitaciones anuladas y anticipadas.

34. Se publica la relación completa de proveedores, adjudicatarios y/o contratistas y la cuantía económica.

35. Se publica el periodo medio de pago a proveedores.

36. Se publican los subsidios otorgados, las respectivas convocatorias y resoluciones.

37. Se publican convenios firmados y sus especificaciones.

\section{Comunicación Institucional}

38. Se publican costes y características de las campañas de publicidad institucional en los medios

39. Se publican nombres de las empresas o personas que han incumplido contratos.

40. Se publican noticias, informaciones y/u opiniones sobre las actuaciones de los miembros del gobierno relacionadas con la gestión

41. Se publican noticias, informaciones y/u opiniones sobre las actuaciones de los miembros de la oposición y/o de los grupos políticos relacionadas con el control de la gestión del gobierno.

42. Se publica información sobre el desarrollo de las sesiones del Concejo, lo presentado por los diferentes grupos políticos, el debate y los acuerdos. 


\section{Información General}

43. Se publica información histórica sobre el municipio.

44. Se da información sobre la situación del municipio: datos sobre el término municipal, la diversidad social, económica, etc.

45. Se ofrece una agenda de actividades municipales y ciudadanas.

46. Se publica el contacto con la persona responsable de Prensa, Información y/o Comunicación de la Institución.

\section{Participación ciudadana}

47. Se da información en la web sobre la normativa vinculada a la Participación Ciudadana.

48. Se da información en la web de otros mecanismos o entes de participación: consejos territoriales, consejos de ciudad, consejos sectoriales, presupuesto participativo, etc.

49. Se publican las Actas de las reuniones de los otros mecanismos o entes de participación.

50. Se ofrece el directorio de las organizaciones sociales y cívicas del municipio y/o el registro de los grupos de interés.

51. Se ofrecen instrumentos de consultas y/o de participación sobre temas actuales de interés local.

52. Se ofrece en la web la relación de servicios que se prestan y los compromisos ante la ciudadanía.

53. Se proporcionan instrumentos para valorar los servicios y para presentar quejas o sugerencias sobre su funcionamiento. 